Research Article

\title{
Study on a Large-Scale Persistent Strong Dense Fog Event in Central and Eastern China
}

\author{
Hongbin Wang, ${ }^{1,2,3}$ Zhiwei Zhang, ${ }^{1,2}$ Duanyang Liu $\mathbb{D}^{1,}{ }^{1,2,3}$ Yuying Zhu, ${ }^{1,2,3}$ \\ Xuerong Zhang, ${ }^{1,2,3}$ and Chengsong Yuan ${ }^{1,2,3}$ \\ ${ }^{1}$ Key Laboratory of Transportation Meteorology, CMA, Nanjing 210009, China \\ ${ }^{2}$ Nanjing Joint Institute for Atmospheric Sciences, Nanjing 21009, China \\ ${ }^{3}$ Jiangsu Institute of Meteorological Sciences, Nanjing 210009, China
}

Correspondence should be addressed to Duanyang Liu; liuduanyang2001@126.com

Received 13 March 2020; Accepted 14 July 2020; Published 1 August 2020

Academic Editor: Francisco Molero

Copyright (c) 2020 Hongbin Wang et al. This is an open access article distributed under the Creative Commons Attribution License, which permits unrestricted use, distribution, and reproduction in any medium, provided the original work is properly cited.

\begin{abstract}
A large-scale persistent strong dense fog (SDF) event that occurred from December 30, 2016, to January 5, 2017, in central and eastern China is analyzed by using a variety of data, including high-resolution satellite and surface observations, meteorological tower observations, fine-resolution sounding observations, and NCEP/NCAR reanalysis data. The results show the following: (1) The SDF event has the characteristics of long duration, wide influence range, large intensity, and serious air pollution. During the study period, there are 531 stations with SDF events, covering an area of over $360,000 \mathrm{~km}^{2}$. There were five stations in Hebei province where the fog lasted for more than 77 hours, and even some stations did not dissipate during the day. (2) Radiation fog and advection fog alternate in this SDF event, namely, radiation fog (20:00 BT on December 30 to 14:00 on January 1), advection radiation fog (20:00 on January 1 to 08:00 on January 2), radiation fog (night on January 2 to daytime on January 3), and advection radiation fog (night on January 3 to January 5). The characteristic of radiation fog is that the central and eastern part of China was controlled by "L" type high pressure. In the stage of advection radiation fog, the combined effect of weak cold advection and radiation cooling leads to the occurrence of SDF. (3) Regarding the duration of the fog event, the inversion structure is continuously maintained at night and in the morning near the stratum, and when the fog intensity is strong, the inversion intensity is correspondingly large, the fog top is lower than the inversion layer top, and the top of the SDF is between 80 and 400 meters.
\end{abstract}

\section{Introduction}

Fog is a suspension of very small, usually microscopic water droplets in the air, reducing visibility at the Earth's surface. According to international definition, fog reduces visibility below $1 \mathrm{~km}$ (0.62 miles), and the denser the fog is, the lower the visibility is. A dense fog (DF) event reduces visibility to 500-200 m, a strong dense fog (SDF) event reduces visibility to $200-50 \mathrm{~m}$, and an extremely dense fog (EDF) event reduces visibility below $50 \mathrm{~m}$. The fog has a serious impact on sea, land, and air transportation, especially the SDF with visibility less than $200 \mathrm{~m}$, which often results in the shutdown of the freeway, taking off and landing difficulty of airplanes, and suspension of sea transportation. A number of serious transportation accidents occurred because of fog every year; for example, at 07:50 on November 15, 2017, a serial collision accident, which involved more than 30 cars, happened in Yingshang, Fuyang city, Anhui province, with 18 killed and 21 seriously injured, and the visibility in some traffic meteorological stations along the road was less than $50 \mathrm{~m}$. At 06:00 on November 6, 2016, Shanghai Central Meteorological Station issued an orange warning signal of dense fog. In the morning of the same day, two rear-end collision accidents happened on S32 road in Pudong district, Shanghai, because of dense fog, with 9 killed and 43 injured. On the morning of November 17, 2012, the visibility on 
Qingxin Freeway decreased sharply to less than $20 \mathrm{~m}$, a couple of cars crashed, and many people were injured. On December 2, 2009, 15 cars collided in Lihue Section of Ninglian Freeway due to dense fog, with 3 killed and 26 injured.

Fog formation is affected by many complex physical processes in the boundary layer, such as thermal, dynamic, radiation, aerosol, and microphysical process, as well as surface condition [1-3]. Fog, moreover, usually has the characteristics of rapid generation and burst reinforcement, which makes it become very difficult to forecast in disastrous weather. A large number of external field observation experiments and numerical simulation works have revealed the structure characteristics of fog and atmospheric boundary layers during the formation and development of fog. In the early days, Eldridge [4] observed and analyzed the distribution of fog droplet spectrum, water content, and visibility. Roach et al. [5] carried out an integrated observation of fog in Elmira Valley near New York in 1970 and analyzed the relationship among fog droplet spectrum distribution, water content, numerical density, and conventional meteorological elements combined with numerical simulation. Hudson [6] observed the distribution of fog droplets and cloud condensation nuclei in several places of the west coastline of America and found that the microphysical characteristics of fog change greatly with the concentration change of condensation nuclei and the visibility also changes greatly. Atmospheric aerosol particles can promote and enhance the formation of fog, mainly because the existence of a large number of aerosol particles reduces the size of fog droplet particles, and more and smaller particles have a larger surface area under the same liquid water content, which leads to the increase of optical thickness and the influence on radiation [7-11]. At the same time, some water-soluble aerosol particles absorb water and grow, forming high-concentration liquid particles, which can form fog droplets in the subsaturated condition [12]. Many scholars have observed and simulated the formation, dissipation mechanism, microphysical characteristics, and chemical composition of fog in different areas of China [13-19]. For example, Li et al. [20, 21] have carried out a large number of fog-observation experiments in Chongqing, Nanjing, and other places. Yang et al. [22] analyzed the boundary layer structure characteristics and the physical mechanism of dense fog process by using the external field test data such as tethered balloon boundary layer detection system, vorticity covariance measurement system, fog droplets spectrometer, and automatic weather station, which occurred in Nanjing in winter with a thickness of $600 \mathrm{~m}$ and lasted for nearly $14 \mathrm{~h}$. It was pointed out that the joint influence of radiation cooling and low-level advection led to the continuous uplift of the surface fog. Eventually, the ground fog passes up and low clouds pass down to form a dense fog event.

There are relatively more studies on the microscopic characteristics of burst reinforcement of fog [23-27]. Li et al. [28] summarize the research results of dense fog in China, including the burst reinforcement features of strong dense fog (SDF) formation, the microphysical process of the fog body enhancement, the causes of burst reinforcement, and the characteristics of the boundary layer structure. The study on the long-term variation characteristics of fog and haze from meteorological stations shows that the annual haze day in China shows an obvious increasing trend, while the foggy day shows a decreasing trend [29-31].

According to observations, the fog event is often persistent. At the beginning of December 2013, the SDF lasted for 10 days in Jiangsu province. Jiao et al. [32] analyzed the formation and maintenance mechanism of the SDF. In January 2013, the serious smog event in eastern China caused serious harm to transportation and human health. The daily evolution of atmospheric circulation background field and meteorological field had an important impact on this persistent large-scale strong smog event [33]. Liu et al. [34] analyzed the persistence of smog in Jiangsu province and the formation mechanism of one of the dense fog events. The study shows that there is a process of mutual transformation and interaction between fog and haze. Ma et al. [35] analyzed the synoptic system and the reasons for the long maintenance of fog event for 12 consecutive days in central and southern Hebei province, as well as the thermodynamic and dynamic structural characteristics. Wu et al. [36] analyzed the water vapor transport and the inverse temperature characteristics of a continuous dense fog event in south-central of North of China during February 13-14, 2006.

The existing studies are mainly focused on the analysis of the thermal, dynamic, and water vapor conditions of the regional persistent fog process, but few studies have been done on the horizontal distribution of persistent SDF and the evolution characteristics of the vertical structure across the region combined with vertical observation data. From December 30, 2016, to January 14, 2017, a dense fog event occurred in central and eastern China for half a month. Based on the high-resolution satellite and ground observation data, Tianjin $255 \mathrm{~m}$ meteorological tower data, multistation second-level sounding data, and NCEP/ NCAR $1^{\circ} \times 1^{\circ}$ reanalysis data, we analyze and study the large range strong dense fog process before January 5 , 2017, in this paper.

In this paper, we examine the evolution of the strong dense fog event in central and eastern China. The weather characteristics of this process are analyzed, the cause of the formation of the SDF event is studied, and the scientific basis for the short-term forecast of the SDF event is provided. The paper is organized as follows. The stations and data used are described in Section 2. We analyze the fog event synoptic system and boundary layer features in Section 3. The conclusions are given in Section 4.

\section{Stations and Data}

2.1. Ground Weather Station Data. In this paper, the data of 915 stations in the study area of 2400 national meteorological stations in China $\left(110^{\circ}-123^{\circ} \mathrm{E}, 29^{\circ}-42^{\circ} \mathrm{N}\right)$ from December 30, 2016, to January 5, 2017, are used, including 5minute resolution data of visibility, temperature, humidity, wind direction, wind speed, and 3-hour resolution artificial 
observation data (including weather phenomena). The distribution of 915 stations is shown in blue dots in Figure 1.

2.2. Radiosonde Sounding Data. The fine-resolution data of 16 radiosonde sounding stations (twice a day at 08:00 and 20: $00 \mathrm{BT}$, Beijing time, the same below) in the range of the study area is used, and the distribution of the sounding station is shown by red five-pointed stars in Figure 1.

2.3. Observation Data of Tianjin Meteorological Tower. Tianjin Meteorological Tower is located in the south of Tianjin $\left(117.1^{\circ} \mathrm{E}, 39.1^{\circ} \mathrm{N}\right)$ with a height of $255 \mathrm{~m}$. There are 15 layers of temperature, humidity, and wind direction and wind speed profile observation data in the tower, with corresponding heights of $5 \mathrm{~m}, 10 \mathrm{~m}, 20 \mathrm{~m}, 30 \mathrm{~m}, 40 \mathrm{~m}, 60 \mathrm{~m}$, $80 \mathrm{~m}, 100 \mathrm{~m}, 120 \mathrm{~m}, 140 \mathrm{~m}, 160 \mathrm{~m}, 180 \mathrm{~m}, 200 \mathrm{~m}, 220 \mathrm{~m}$, and $250 \mathrm{~m}$, and the temporal resolution of data is $1 \mathrm{~min}$. The location of the Tianjin Meteorological Tower is shown in the square in Figure 1. In this paper, the meteorological elements information of the 15 layers of the tower from December 30, 2016, to January 5, 2017, is used, but there is a shortage of data from 00:00 to 08:00 on January 1, 2017.

2.4. NCEP/NCAR Reanalysis Data and Satellite Data. NCEP/NCAR reanalysis data were used to analyze the meteorological factors and weather patterns. The data on $1^{\circ} \times 1^{\circ}$ grid was prepared operationally every 6 hours. The new generation of Japanese geostationary meteorological satellite Himawari- 8 is equipped with visible and infrared scanning radiometer AHI (Advanced Himawari Imager). Himawari-8/AHI has a great improvement in the number of spectral channels and the spatiotemporal resolution compared to the previous generation of geostationary satellites. The original resolution data of 16 bands of Himawari- 8 from December 30, 2016, to January 5, 2017, are used to monitor the development and evolution of fog events.

\section{Results and Discussion}

3.1. The Evolution of the Wide Range, High Intensity, and Long Duration Fog. From December 30, 2016, to January 14,2017 , persistent strong dense fog (SDF) events occurred in central and eastern China. Among them, there was a wide range of SDF events from January 1 to 4, 2017, and there were more than 150 SDF stations per day. Wide range SDF with visibility less than $200 \mathrm{~m}$ appeared in central and southern Hebei, Beijing, Tianjin, Shandong, eastern Henan, Jiangsu, Anhui, and other places in China, and extremely dense fog (EDF) event with visibility less than $50 \mathrm{~m}$ appeared in some areas. There are 531 stations with SDF that occurred during the study period. Therefore, this is the focus period of this study.

At 19:00 on December 30, 2016, fog events first occurred in Baoding, Cangzhou, Hengshui, and Xingtai areas in south-central Hebei province, showing northeast-southwest direction and gradually spreading to the surrounding area, and the intensity was strengthened. By 02:00 on December
31 (Figure 2(a)), 18 stations in this area had been strengthened into SDF events, including Anguo Station and Anping Station, where there were EDF events with visibility less than $50 \mathrm{~m}$, which indicated that the SDF had expanded to the horizontal level. By 8:20 on December 31 (Figure 2(b)), the number of SDF stations increased to 72, including most areas in central and southern Hebei province and parts of Tianjin. After that, with the increase of solar radiation, the number of dense fog stations began to decrease. However, even when the number of SDF stations in the afternoon was the lowest (14:10, Figure 2(c)), 11 stations still witnessed SDF, indicating that the SDF event continued during the day. This feature still occurred during the day on January 1; for example, there were still 23 stations with SDF when it was the least number of SDF stations in the afternoon (16:00, Figure 2(e)). At 5:40 on January 1 (Figure 2(d)), the number of SDF stations reached 153, twice the maximum number of stations on the $31^{\text {st }}$, and there were two SDF event centers: the main body was still in Hebei and Tianjin, but it spread southward, and the other was in southeastern Jiangsu province. By 5:00 on January 2 (Figure 2(f)), the range of SDF events in Hebei province moved obviously toward the south, and SDF events appeared in the southcentral part of Hebei, Tianjin, southern Beijing, northern and western Shandong, and northeast Henan province. There were also fog events in most parts of the Yangtze River in the north of Jiangsu, but only a few stations reached SDF. At 14:30 on January 2 (Figure $2(\mathrm{~g})$ ), the visibilities of some stations in the southwest of Shandong and the eastern part of Henan were lower than $500 \mathrm{~m}$, and the fog in other areas was dissipated. By 18:00 (Figure 2(h)), the fog event was strengthened to the SDF event. Compared with the position where the dense fog event first appeared on the $31^{\text {st }}$ and $1^{\text {st }}$, the central position continued to move southward at this time. By 4:50 on January 3 (Figure 2(1)), the influence of the SDF event was significantly extended southward, as well as in most areas of Jiangsu and Anhui provinces, compared with 5:00 on November 2. The dense fog event in the afternoon of the $3^{\text {rd }}$ was weakened, and Figures $2(\mathrm{~h})-2(\mathrm{o})$ show the process of the rapid growth and dissipation of the fog event from the afternoon of the $2^{\text {nd }}$ to the afternoon of the $3^{\text {rd }}$. By January 3, 18:00 (Figure 2(p)), two strong dense fog centers were formed: one in the south-central Hebei, and the other from the middle of Shandong to the southeast of Henan, all of which showed a northeast-southwest trend. After that, the two strong dense fog centers spread around. By 5:00 on the $4^{\text {th }}$ (Figure 2(q)), the number of SDF stations reached 294, with affecting range including central and southern Hebei, Tianjin, southern Beijing, Shandong, eastern Henan, parts of northern Anhui province, and the north of Jiangsu province. After 23:00, the wind speed increased, weak precipitation appeared, the visibility was gradually changed, and the SDF event in the study area was weakened in a wide range by 14:00 (Figure 2(r)) on January 5. Since then, fog and SDF events continued until January 15. It can be seen that the fog event is of wide range, high intensity, and long duration.

To describe the intensity of the fog event, Figure 3 shows the number of stations that have observed the fog at different 


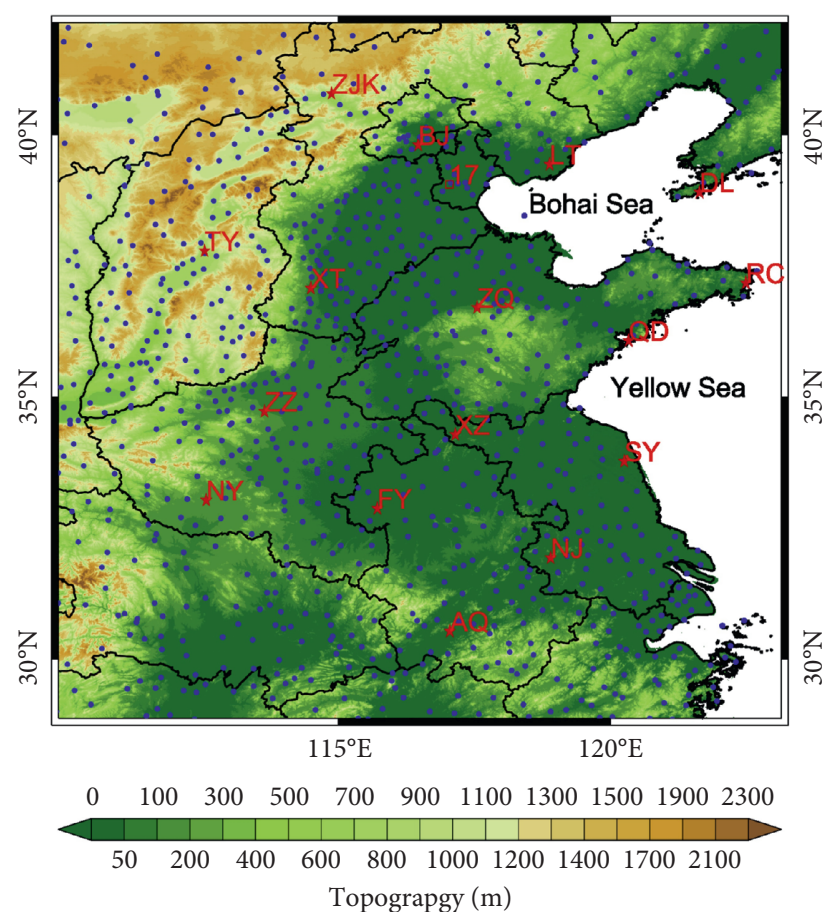

FIgURE 1: Altitude and stations distribution in the study area (blue dots are national meteorological stations in the study area, red fivepointed stars are the distribution of sounding stations, and the red square is the location of Tianjin Meteorological Tower).

levels in the study area from December 30, 2016, to January 10, 2017. At 20:00 on December 30, 2016, there was a strong dense fog at Xinhe Station in Hebei province. By December 31 , the number of SDF stations increased to 7 , and to $08: 20$, the number of SDF stations increased to 72. From December 31,2016 , to January 4, 2017, there were more than 70 stations witnessing SDF events per day, among which 260 (04:50) and 294 (05:00) stations were the most stations with SDF events on January 3 and 4 , respectively. Table 1 lists the maximum station points and the corresponding time of fog, dense fog, strong dense fog, and extremely dense fog events in the daily study area from December 30, 2016, to January 5 , 2017. On January 3, the maximum numbers of stations (corresponding to occurrence time) of fog, dense fog, strong dense fog, and extremely dense fog event were 431 (06:10), 349 (04:50), 260 (04:50), and 55 (06:40), respectively. On January 4, the maximum number of stations (corresponding to the occurrence time) was 439 (06:30), 359 (04:30), 294 (05: $00)$, and 57 (01:40), respectively. It can be seen that the intensity of the fog event is particularly high, and the distribution of SDF events is wide. What is more serious is that the duration of SDF events is particularly long, such as Shenzhou Station, Guangzong Station, Dacheng Station, Anping Station, and Hejian Station in Hebei province, accounting for more than $45 \%$ of the study period. The duration of fog is $128.8 \mathrm{~h}, 154.0 \mathrm{~h}, 124.5 \mathrm{~h}, 131.7 \mathrm{~h}$, and $128.0 \mathrm{~h}$, accounting for more than $75 \%$ of the study period, while the duration of the SDF event is $81.6 \mathrm{~h}, 80.0 \mathrm{~h}, 79.8 \mathrm{~h}, 77.5 \mathrm{~h}$, and $77.2 \mathrm{~h}$. The SDF in stations in other provinces also last a long time.
3.2. The Synoptic System with Persistent Strong Dense Fog Event on a Large Scale. The $500 \mathrm{hPa}$ average potential height field and temperature field (Figure 4(a)) from December 30, 2016, to January 5, 2017, show that the high-latitude circulation in Eurasia was straight and the meridional airflow was weak. The airflow in the southern branch of the Bay of Bengal was stable and the eastward movement speed was slow. North China and Huanghuai region were controlled by a wide range of warm and high-pressure ridges, and there was no obvious temperature advection. The day-to-day $500 \mathrm{hPa}$ height field shows that most of the high air was traveling to the east in a small short wave channel, and the weak synoptic system was not conducive to the formation of clouds and precipitation but was favorable to the formation of the ground pressure field and the fine weather and provided a suitable environment background for the occurrence of persistent fog event. The mean sea level pressure field from December 30, 2016, to January 5, 2017 (Figure 4(b)), shows that the large-scale persistent fog area in central and eastern China was in the uniform pressure field, and the large-scale stable synoptic system was an important reason for the maintenance of large-scale fog event for a long time.

The surface pressure field shows that (Figure 5), from 20: 00 on December 30 to 14:00 on January 1 (stage I), the central and eastern parts of China were controlled by the pressure field at the back of the high pressure for a long time. Fog event first appeared in the south-central part of Hebei province and gradually spread around, and the intensity of fog was strengthened. The fog area was mostly affected by the weak southward wind with wind speed mostly below $1 \mathrm{~m} / \mathrm{s}$. From the Himawari- 8 satellite cloud picture (Figure 6), we can see that, from 20:00 on December 30 to 08:00 on January 1 , except for the night of January 1, there was a narrow band system between the junctions of Henan, Hebei, and central Shandong, and there was no cloud cover at other times, which was beneficial to the cooling of longwave radiation at night. It can be observed that the fog event at this stage is a radiation fog event.

At 20:00 on January 1, affected by the cold and high pressure spreading from north to south in the Hetao area, the north of fog area changed from south wind to north wind and continued to spread south. By 08:00 on 2 January, the fog area expanded to the Jianghuai area, and the wind direction of the whole fog area changed to the north wind, and the wind speed increased to more than $2 \mathrm{~m} / \mathrm{s}$. From the satellite cloud picture at 14:00 on January 1, it can be observed that clouds have been covered in most areas of North China and the Huanghuai area and gradually moved south and east. By 21:00 on January 1, the sky over central and southern Hebei has turned to clear, and by 08:00 on January 2, except in southern Anhui and southern Jiangsu, the sky of other areas had become clear, and the clear sky area coincided with the fog area. The fog event in this stage (from 20: 00 on January 1 to $08: 00$ on January 2, stage II) was affected not only by night radiation temperature decreasing but also by cold air in the north, which can be called advection radiation fog. At 14:00 on January 2, Shandong, Henan, and Hebei were in the high-pressure control area of the ground, 


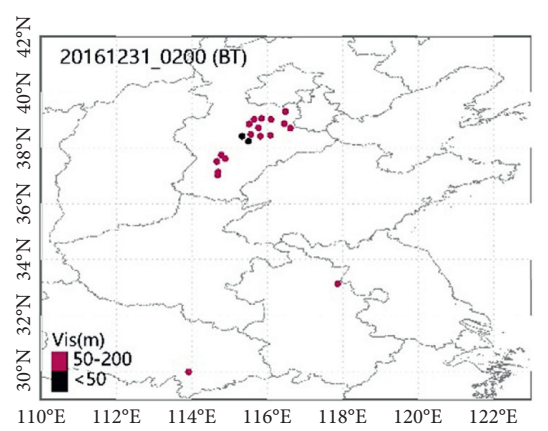

(a)

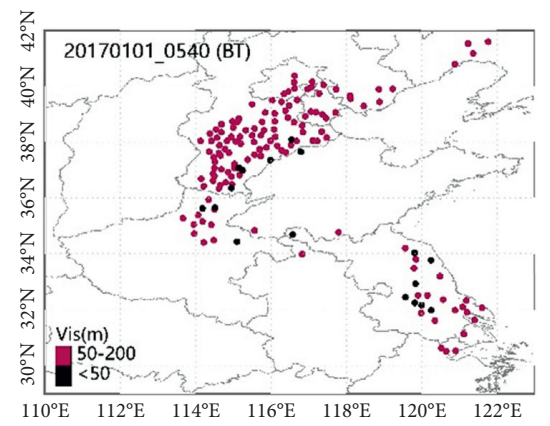

(d)

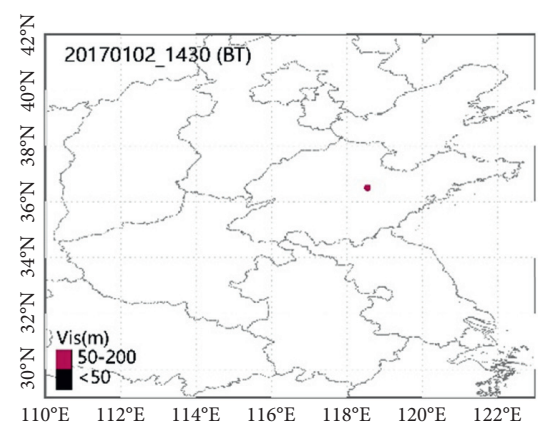

(g)

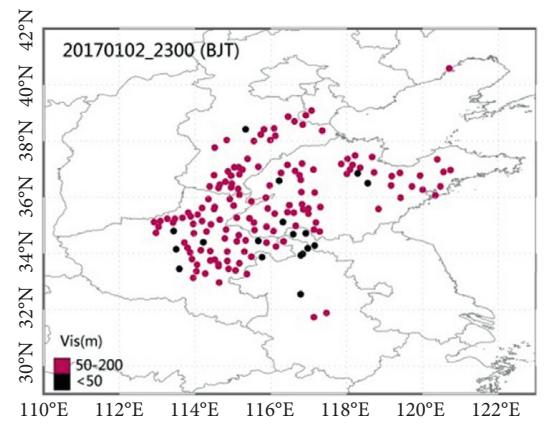

(j)

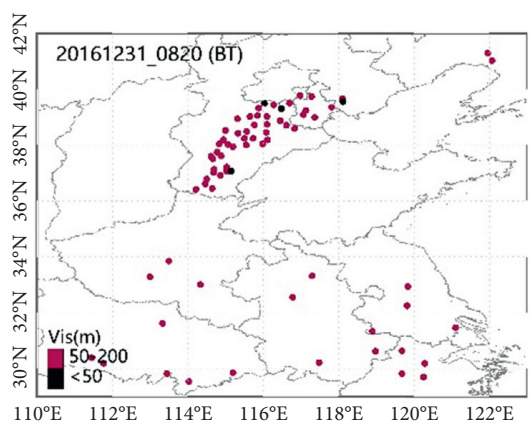

(b)

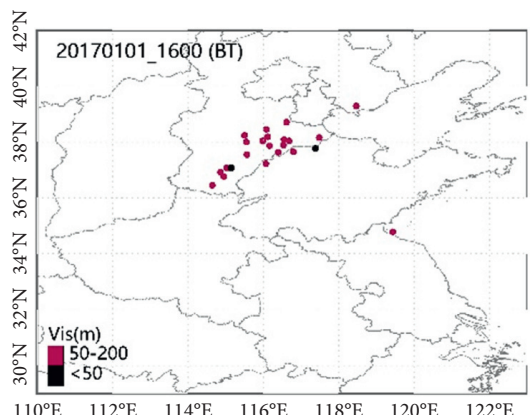

(e)

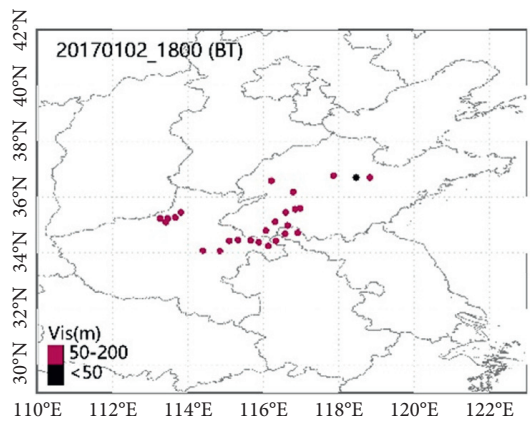

(h)

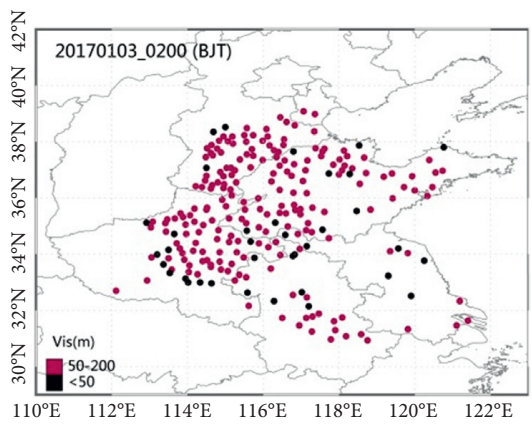

(k)

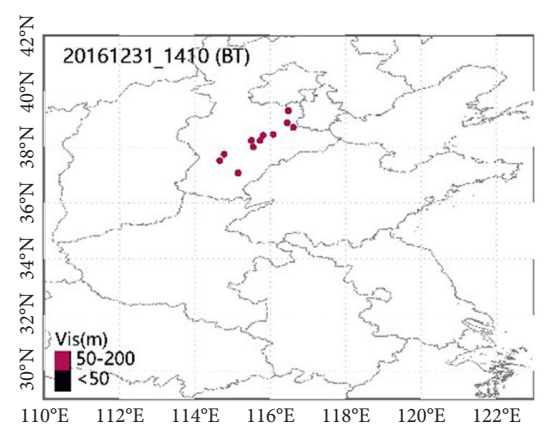

(c)

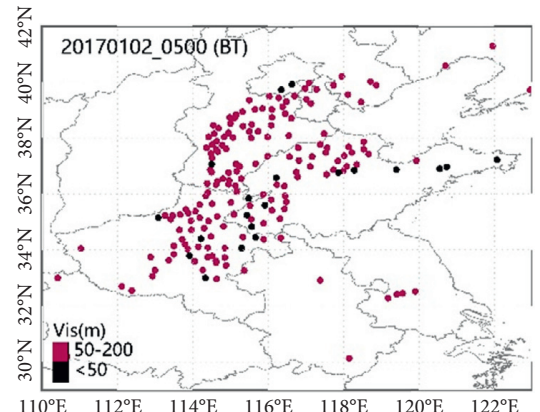

(f)

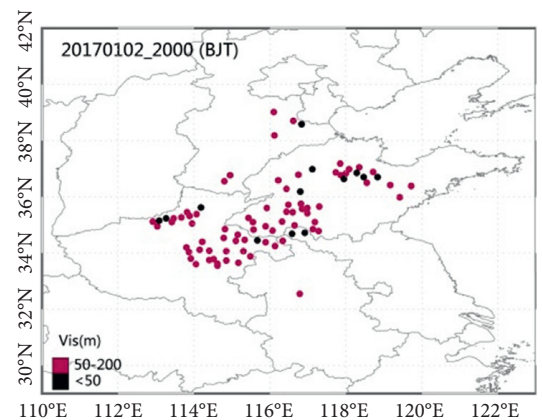

(i)

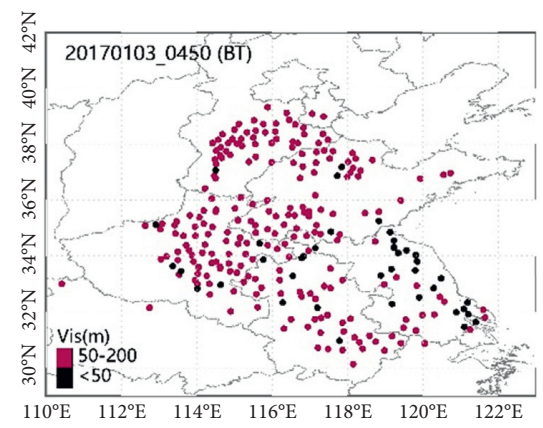

(1)

Figure 2: Continued. 


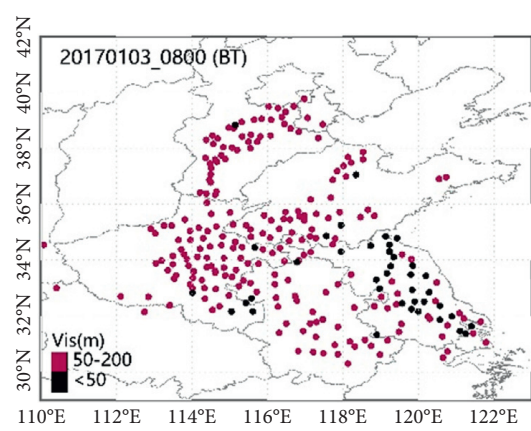

(m)

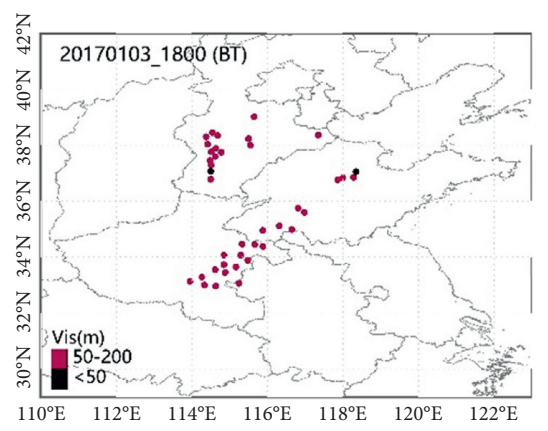

(p)

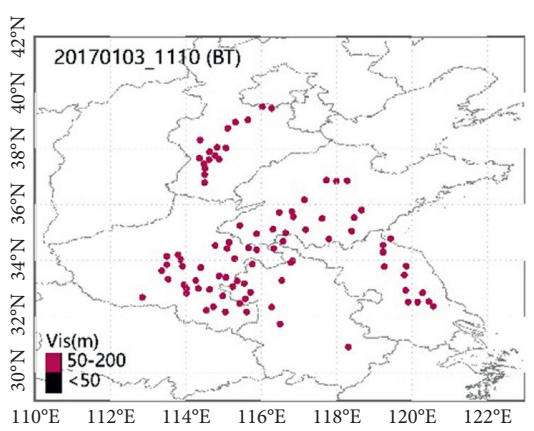

(n)

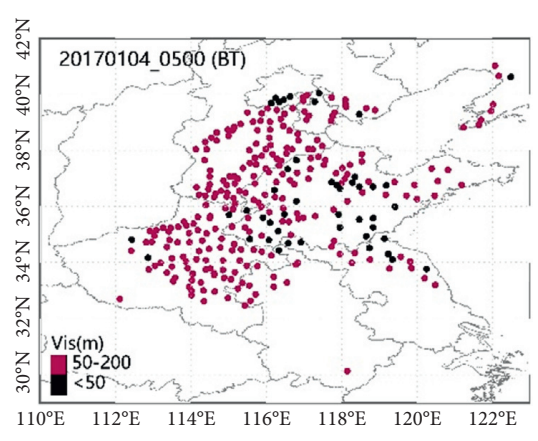

(q)

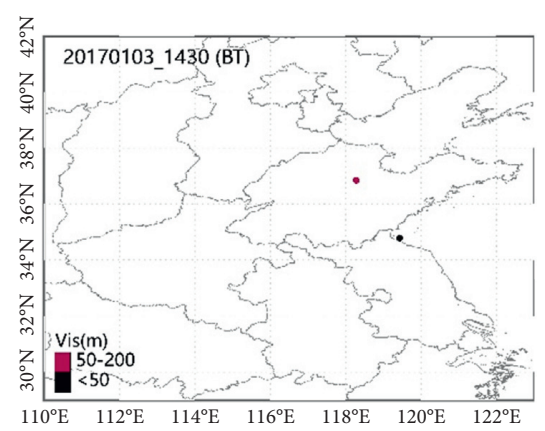

(o)

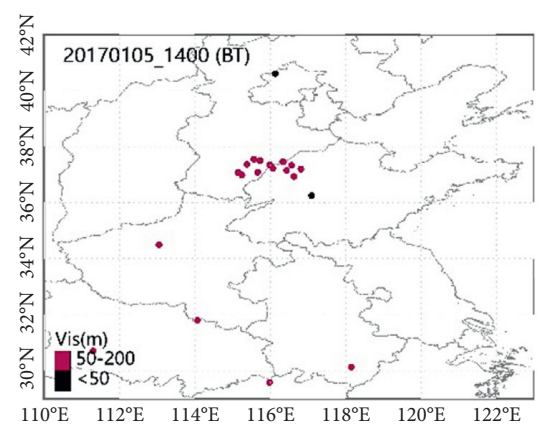

(r)

Figure 2: Evolution of wide range persistent SDF event from December 30, 2016, to January 5, 2017 (the red and black dots represent SDF and EDF stations, respectively). (a) 20161231_0200 (BT). (b) 20161231_0820 (BT). (c) 20161231_1410 (BT). (d) 20170101_0540 (BT). (e) 20170101_1600 (BT). (f) 20170102_0500 (BT). (g) 20170102_1430 (BT). (h) 20170102_1800 (BT). (i) 20170102_2000 (BJT). (j) 20170102_2300 (BJT). (k) 20170103_0200 (BJT). (l) 20170103_0450 (BT). (m) 20170103_0800 (BT). (n) 20170103_1110 (BT). (o) 20170103_1430 (BT). (p) 20170103_1800 (BT). (q) 20170104_0500 (BT). (r) 20170105_1400 (BT).

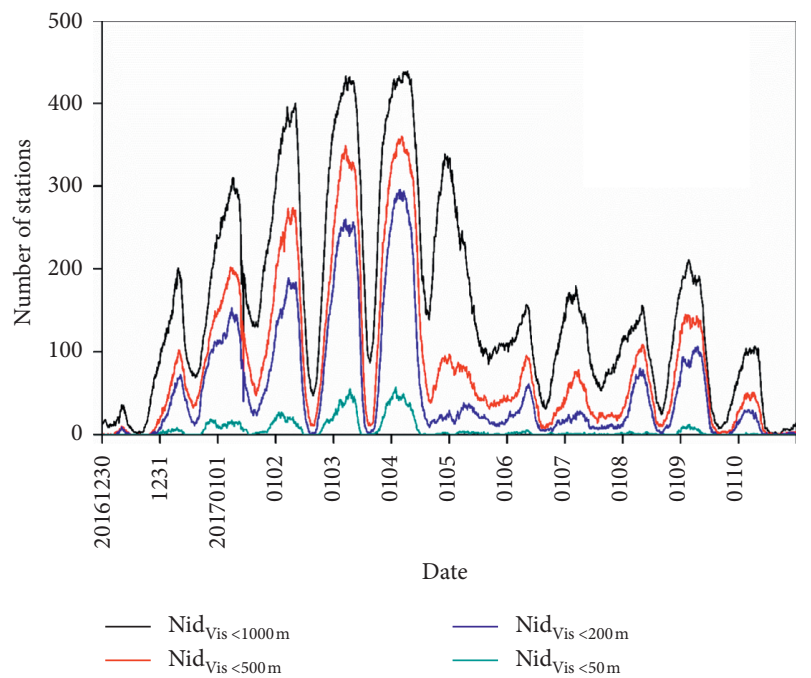

FIGURE 3: The number of stations that have observed the fog, DF, SDF, and EDF in the study area from December 30, 2016, to January 10, 2017.

and the temperature of the daytime increased and the visibility of most of the stations was recovered.

At 20:00 on January 2, the central and eastern parts of China were controlled by "L" type high pressure. Many stations in Shandong and Henan had the phenomenon of SDF events. Compared with the first position of the SDF event on January 1 , the southward movement of the center of the SDF event was consistent with the southward movement of the high pressure in the north of the Hetao area. By 05:00, the number of fog pixels identified by Himawari- 8 satellite in the whole area reached 82,371 , with an area of more than $360,000 \mathrm{~km}^{2}$. By 08:00 on January 3, under clear weather radiation in the " $\mathrm{L}$ " type high-pressure control area, the SDF area covered the central and southern Hebei, Shandong, central and eastern Henan, Jiangsu, and Anhui provinces, and the wind speed in the fog area was generally less than $2.0 \mathrm{~m} / \mathrm{s}$. By the time of 14:00, in addition to the south-central Hebei, there were fog events or dense fog events in some stations in Shandong and Henan, and the SDF in other areas dissipated. It can be observed that the fog event from 2 January to 3 January (stage III) is a radiation fog event.

From 20:00 on January 3, the ground high-pressure system in the northern part of Inner Mongolia was gradually moved to the east. At 20:00 on January 3, strong fog event appeared in the south-central Hebei, Tianjin, southern Beijing, northern and western Shandong, southeast Henan, and the coastal areas of central Jiangsu under the influence of longwave radiation. By 02:00 on January 4, affected by the high circulation, the cold air in the east penetrated from north to south, the wind direction changed to east or northeast, the wind speed was mostly below $2.0 \mathrm{~m} / \mathrm{s}$, affected by cold advection, and most of the stations developed into SDF event. By 14:00 on January 5, with the increase of cold high pressure, the pressure gradient increased obviously. The 
TABLE 1: Maximum number of stations and corresponding time (BT) of fog, DF, SDF, and EDF in the study area from December 30, 2016, to January 5, 2017.

\begin{tabular}{|c|c|c|c|c|c|c|c|c|}
\hline \multirow{2}{*}{$\frac{\text { Date }}{20161230}$} & \multicolumn{2}{|c|}{$\begin{array}{l}\text { Max Nid }_{1000 m} \\
\text { and time }\end{array}$} & \multicolumn{2}{|c|}{$\begin{array}{l}\text { Max } \mathrm{Nid}_{500 \mathrm{~m}} \\
\text { and time }\end{array}$} & \multicolumn{2}{|c|}{$\begin{array}{l}\text { Max } \mathrm{Nid}_{200 \mathrm{~m}} \\
\text { and time }\end{array}$} & \multicolumn{2}{|c|}{$\begin{array}{l}\text { Max Nid }_{50 \mathrm{~m}} \\
\text { and time }\end{array}$} \\
\hline & 36 & 08:00 & 10 & 08:00 & 9 & 08:00 & 0 & - \\
\hline 20161231 & 201 & 07:20 & 102 & $07: 40$ & 72 & 08:20 & 8 & $06: 50$ \\
\hline 20170101 & 310 & 06:00 & 201 & $05: 40$ & 153 & $05: 40$ & 17 & $05: 40$ \\
\hline 20170102 & 400 & 08:00 & 274 & 07:00 & 189 & 05:00 & 27 & $01: 10$ \\
\hline 20170103 & 431 & 06:10 & 349 & $04: 50$ & 260 & $04: 50$ & 55 & $06: 40$ \\
\hline 20170104 & 439 & $06: 30$ & 359 & $04: 30$ & 194 & 05:00 & 57 & $01: 40$ \\
\hline 20170105 & 339 & 0104 22:00 & 95 & 0104 22:00 & 37 & 08:00 & 4 & $05: 20$ \\
\hline
\end{tabular}

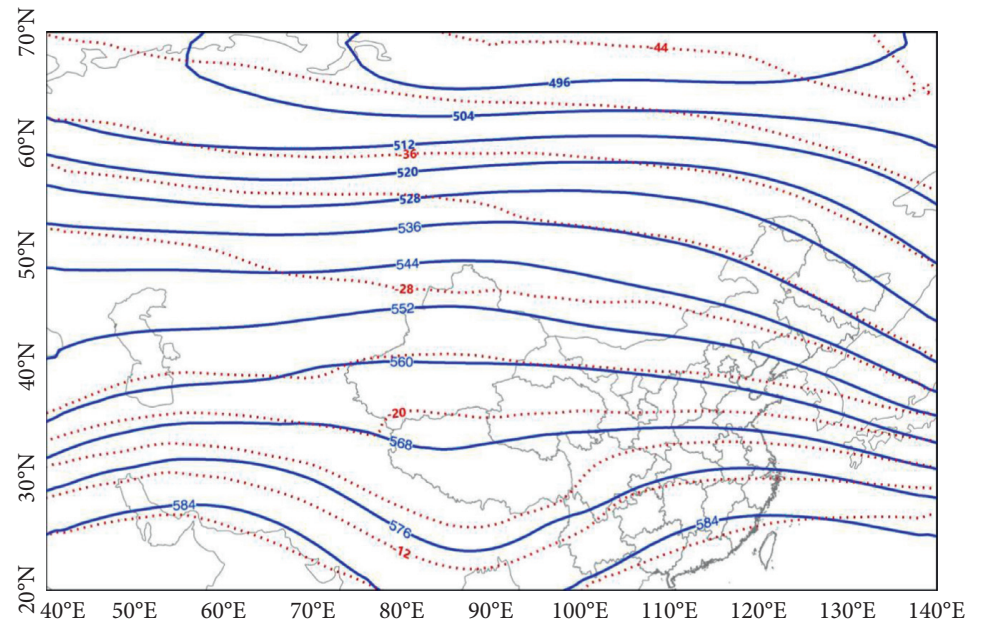

(a)

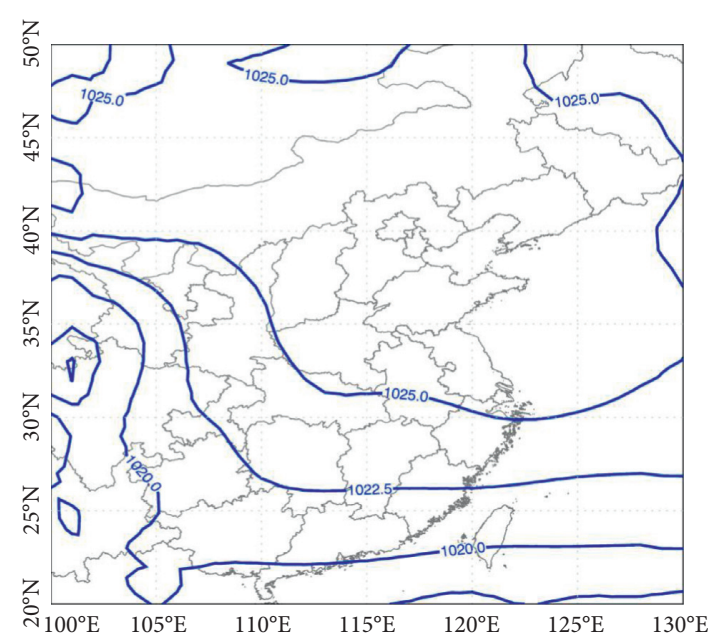

(b)

Figure 4: The $500 \mathrm{hPa}$ mean geopotential height (unit: dagpm) and temperature field (unit: ${ }^{\circ} \mathrm{C}$ ) (a) and mean sea level pressure field (unit: hPa) (b) from December 30, 2016, to January 5, 2017.

wind of most stations was $2.0-4.0 \mathrm{~m} / \mathrm{s}$ east or north wind. Except for the strong fog event at individual stations at the junction of Hebei and Shandong, there was no SDF event in other stations. At this time, it can be observed from the surface of MICAPS map that almost all of the other stations in Hebei, Shandong, Henan, Jiangsu, and Anhui province are covered by the cloud, except that the sky at the junction of Hebei and Shandong has been affected by strong fog event. A large number of clouds can also be seen on the cloud image, and weak precipitation occurs from the evening of January 4 to the daytime of January 5; for example, the precipitations of Baoying station in Jiangsu, Dangshan station in Anhui, Liaocheng station in Shandong, Weishi station in Henan, and Handan station in Hebei were $22.6 \mathrm{~mm}, 12.8 \mathrm{~mm}, 4.8 \mathrm{~mm}, 9.0 \mathrm{~mm}$, and $5.9 \mathrm{~mm}$, respectively. In conclusion, the fog event from the daytime of January 3 to the night of January 5 (stage IV) is still advection radiation fog. It should be pointed out that, due to the slow penetration of cold air in the early stage, under the combined action of cold advection and radiation cooling, the influence range of SDF area in the early morning of January 4 increased, and 294 stations of SDF event appeared, and then the visibility became better with the enhancement of cold air and the appearance of weak precipitation.
3.3. Structural Characteristics of the Atmospheric Boundary Layer. In order to study the characteristics of the atmospheric boundary layer structure in this large area SDF event, the sounding data of boundary layer $(0-1000 \mathrm{~m})$ from December 30, 2016, to January 5, 2017, at 16 national sounding stations in central and eastern China are analyzed in this paper. The results show that there is an inversion layer when the fog event occurs. After the fog event is formed, and with the upward development of the fog, the inversion layer moves to the top of the fog, and the temperature in the fog has wet and heat-isolated distribution. Once the inversion layer disappears, the fog quickly dissipates.

Figure 7 shows the temperature, relative humidity, and wind direction and wind speed profiles of several foggy times in Xingtai Station in Hebei province, which is marked with $\mathrm{XT}$ in Figure 1. Table 2 gives the corresponding time ground visibility and inversion layer strength, thickness, and so on. The length of time of fog event in Xingtai station is $127.7 \mathrm{~h}$, and the SDF event occurs for $58.8 \mathrm{~h}$. These times of fog are SDF events except 20:00 on January 4, and some are still EDF events. It can be observed from the figure and the table that the intensity of the inversion of these hours is relatively large, and the stronger the inversion is, the greater the intensity of the fog event on the ground will be. After the surface fog 


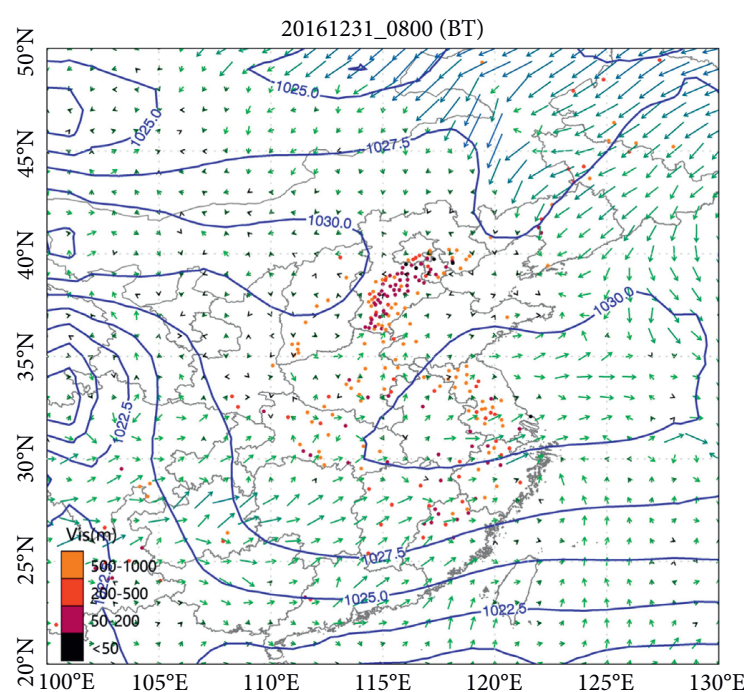

(a)

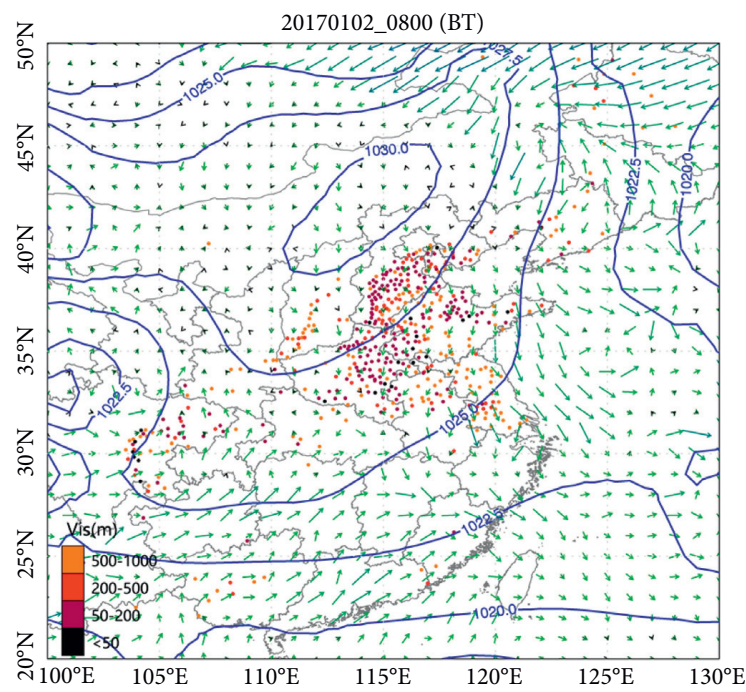

(c)

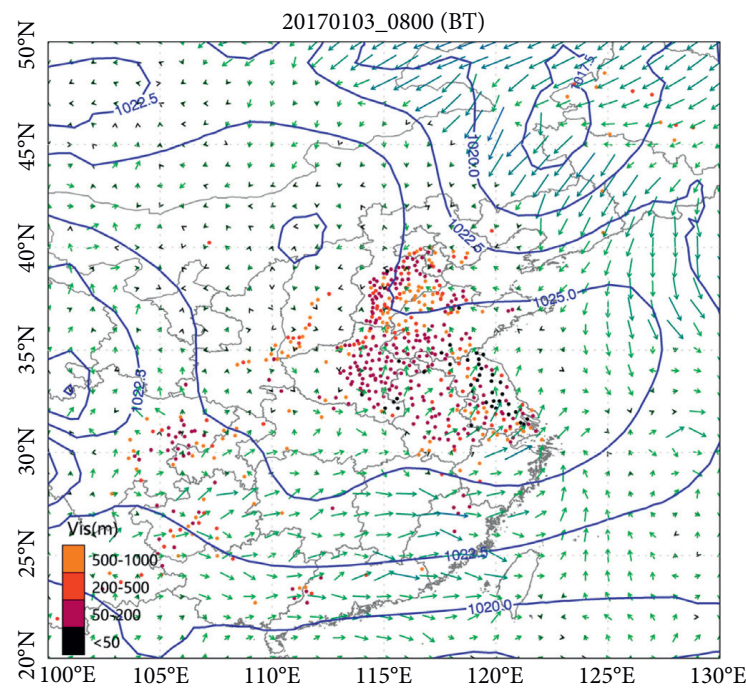

(e)

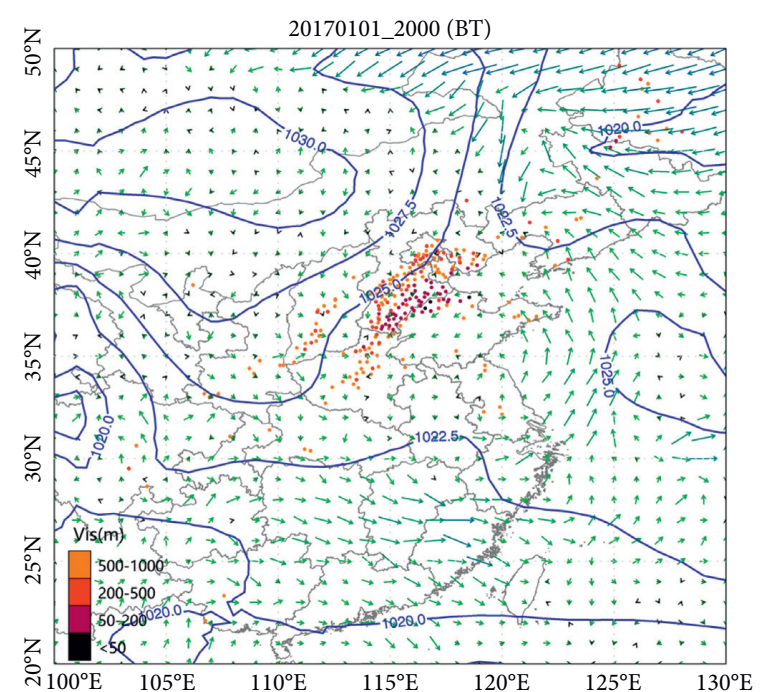

(b)

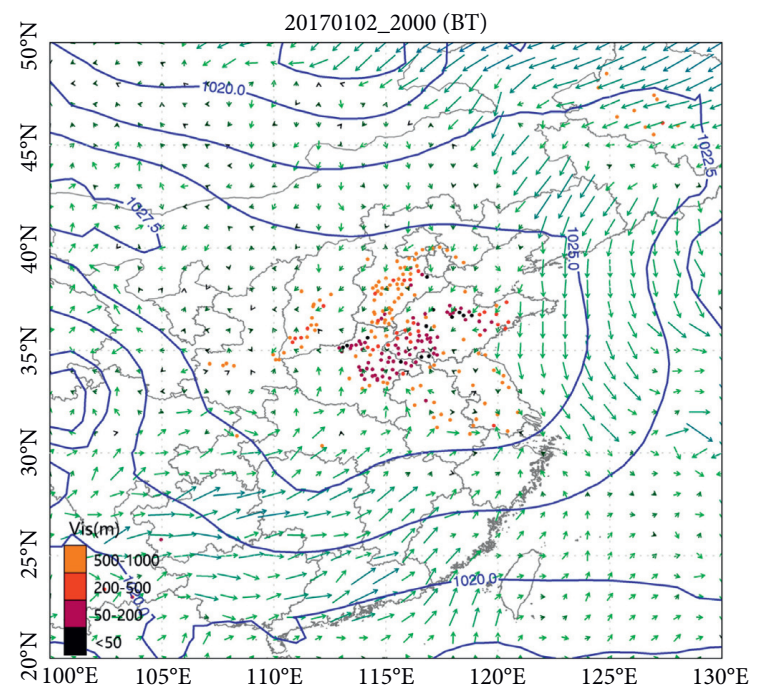

(d)

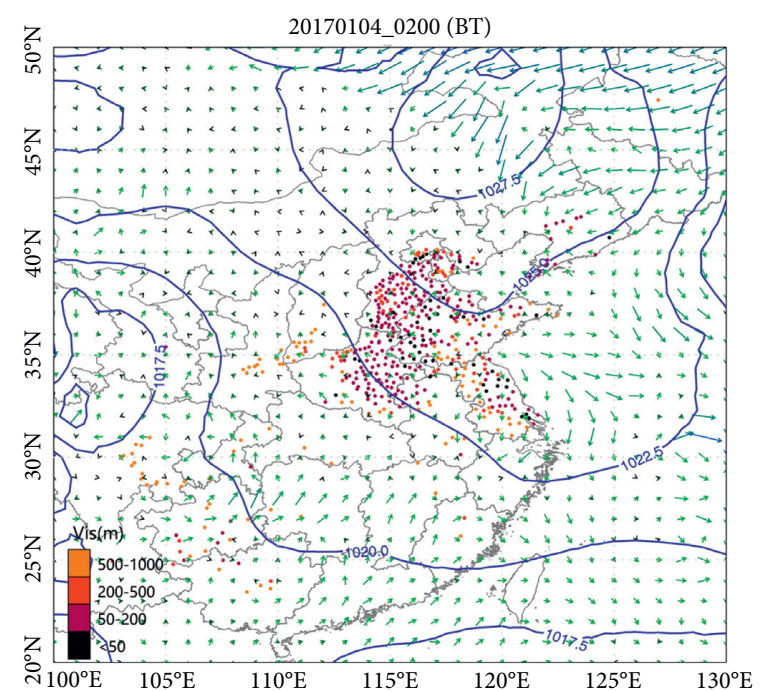

(f)

Figure 5: Continued. 


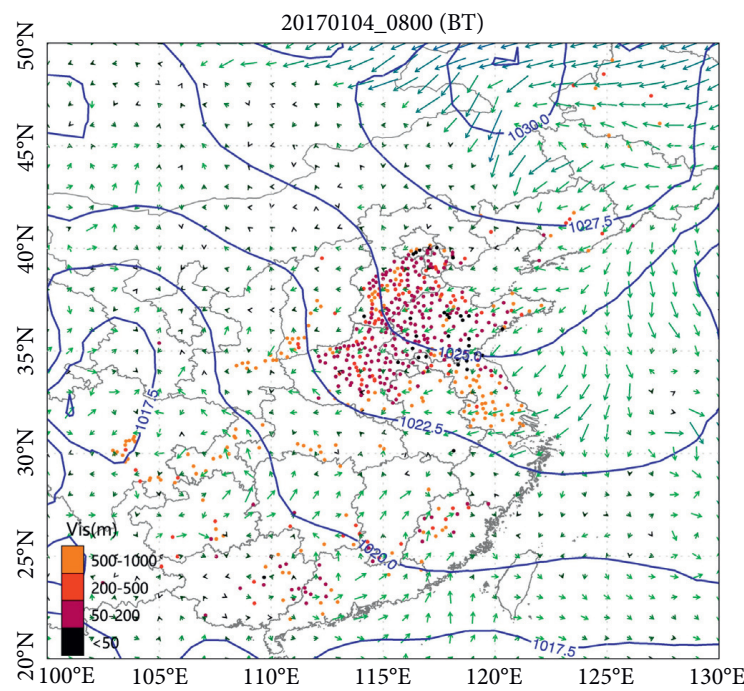

(g)

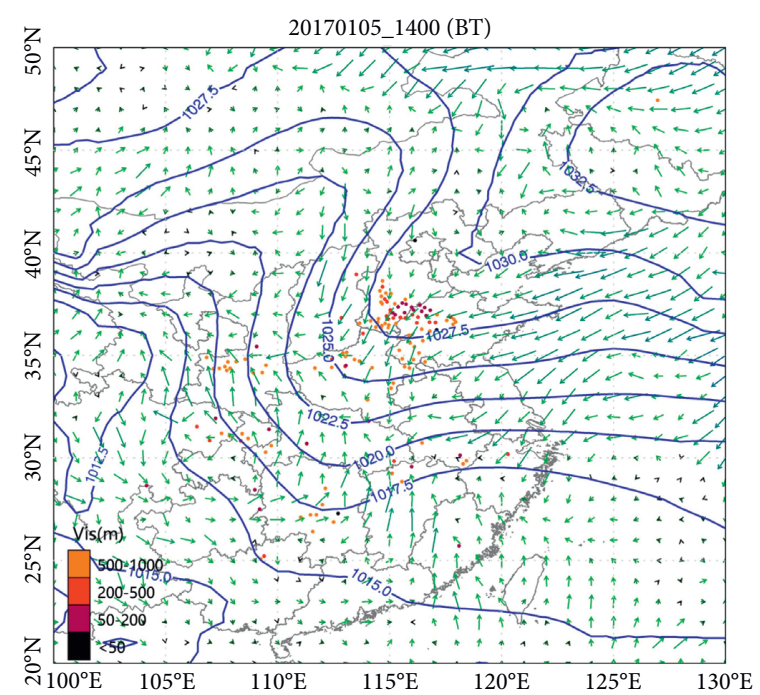

(h)

Figure 5: Synoptic system and wind field on the ground from December 30, 2016, to January 5, 2017. (a) 20161231_0800 (BT). (b) 20170101_2000 (BT). (c) 20170102_0800 (BT). (d) 20170102_2000 (BT). (e) 20170103_0800 (BT). (f) 20170104_0200 (BT). (g) 20170104_0800 (BT). (h) 20170105_1400 (BT).

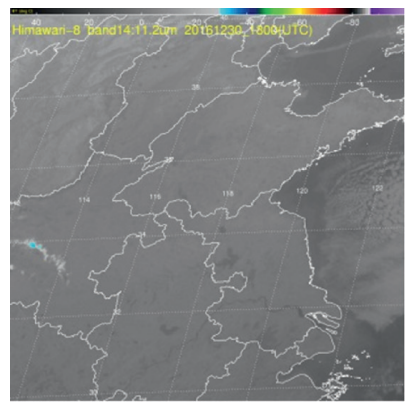

20161231_02:00

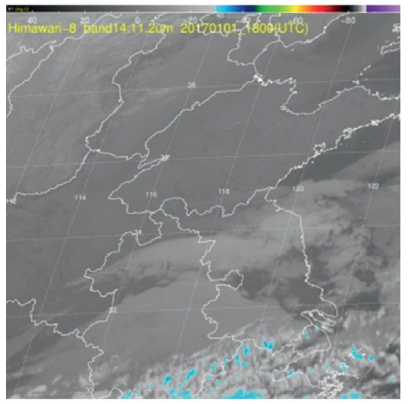

20170102_02:00

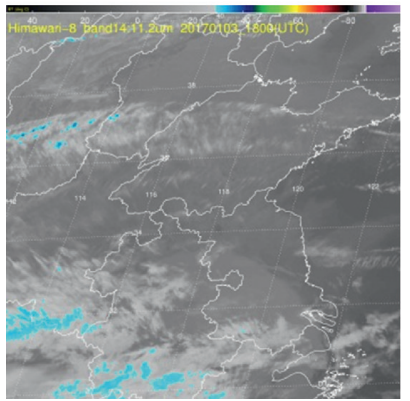

20170104_02:00

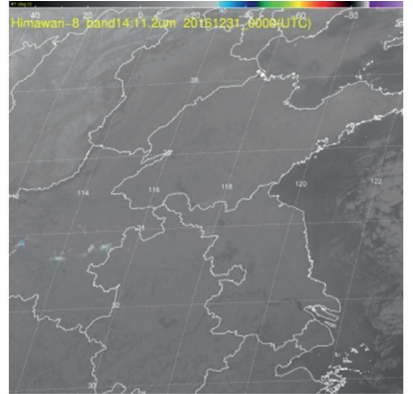

20161231_08:00

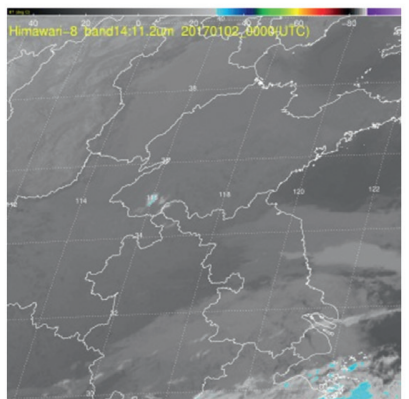

20170102_08:00

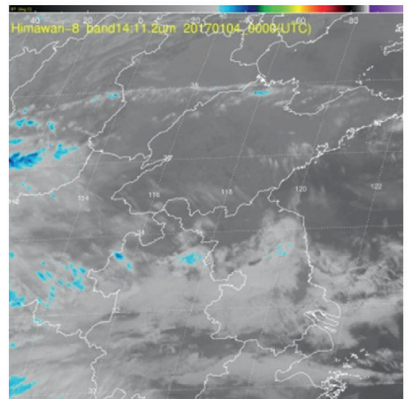

20170104_08:00

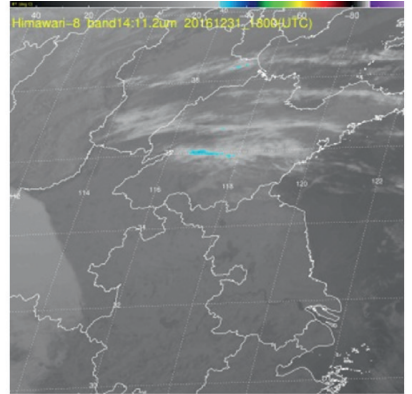

20170101_02:00

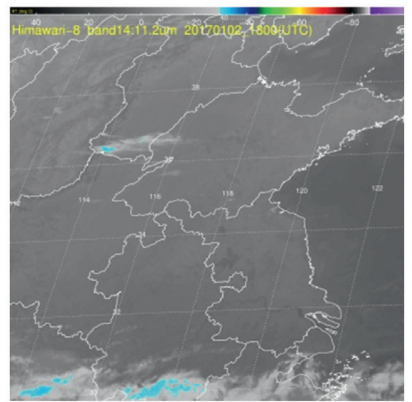

20170103_02:00

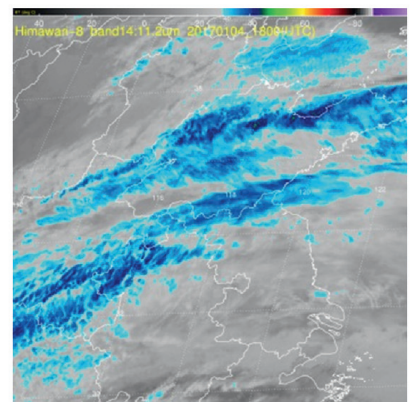

20170105_02:00

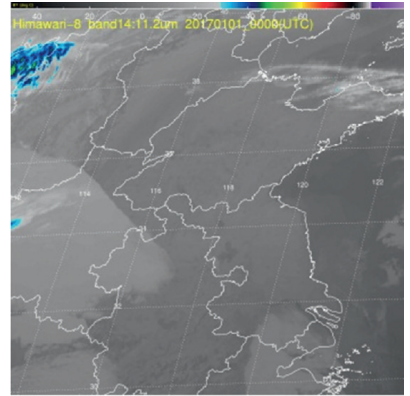

20170101_08:00

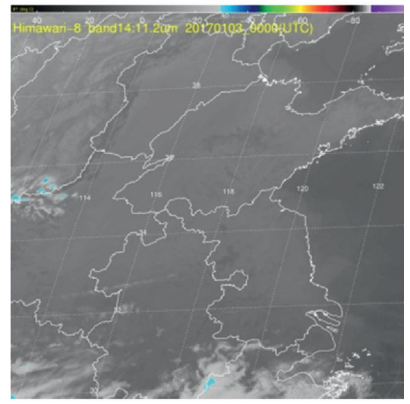

20170103_08:00

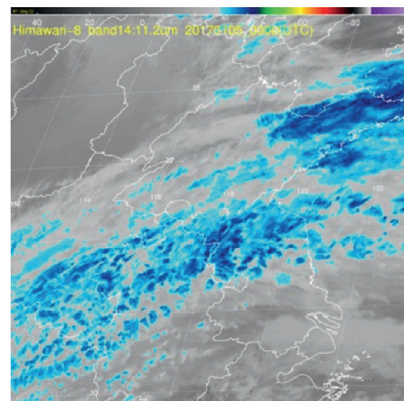

20170105_08:00

FIGURE 6: Himawari-8 satellite $11.2 \mu \mathrm{m}$ channel cloud image at 02:00 and 08:00 every day from December 30, 2016 , to January 5, 2017. 


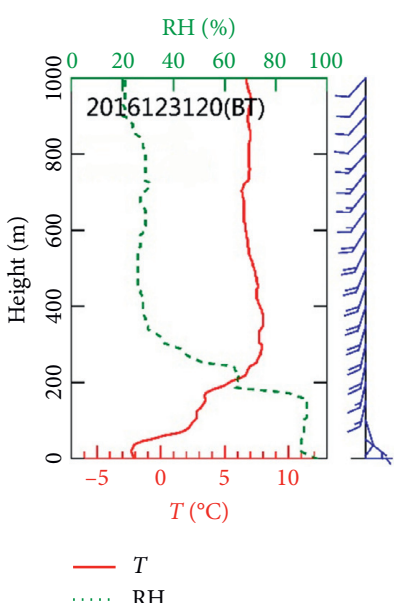

(a)

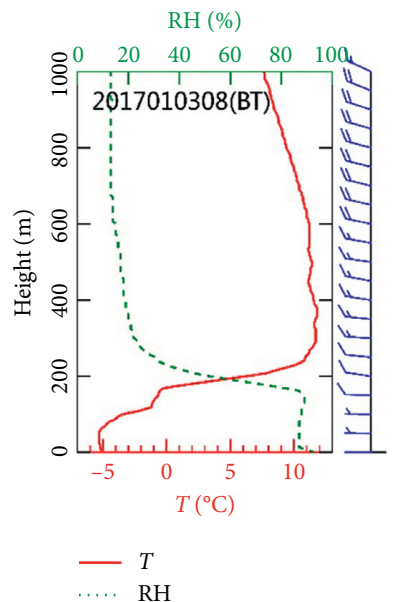

(e)

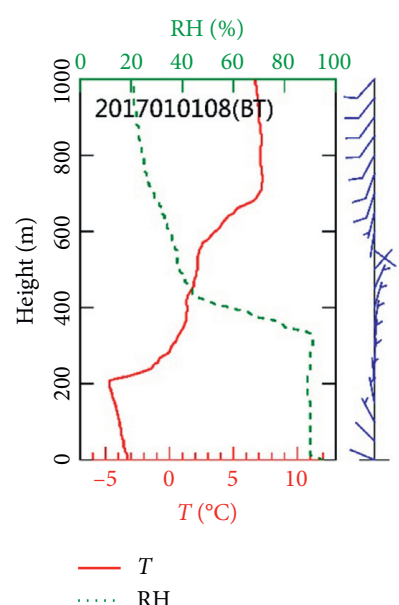

(b)

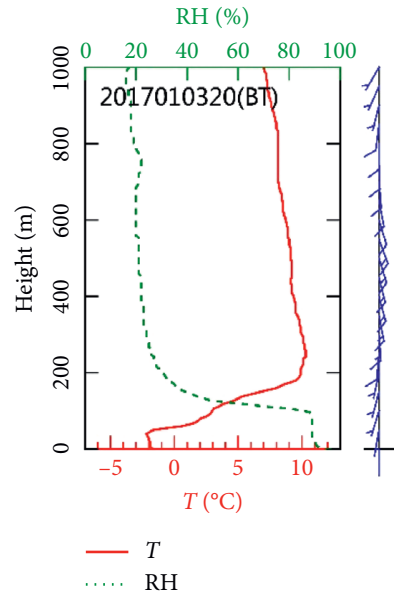

(f)

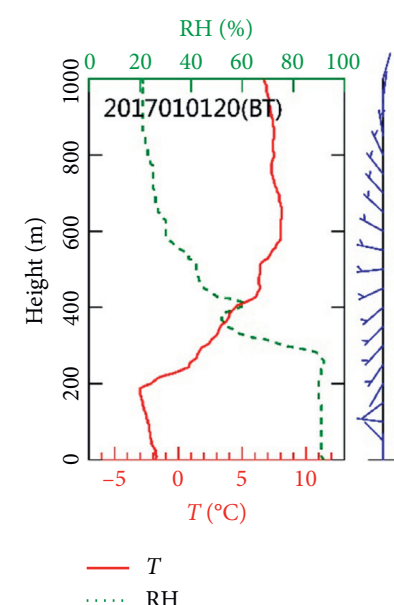

(c)

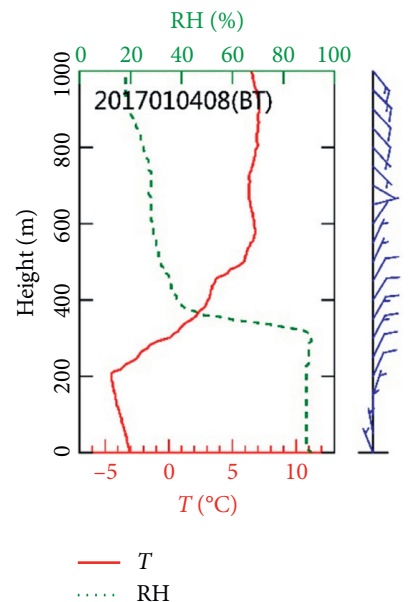

(g)

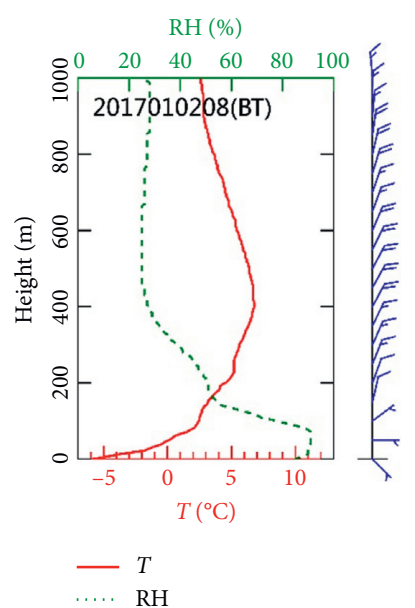

(d)

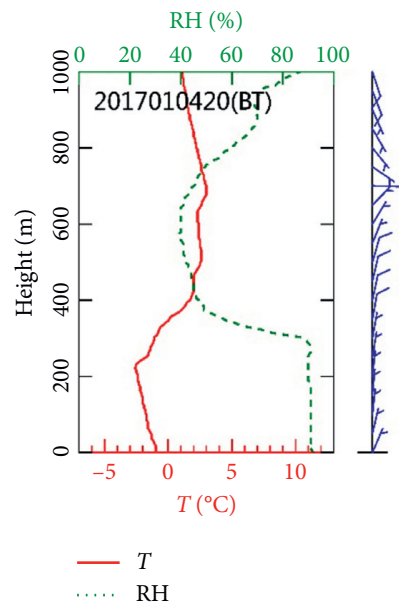

(h)

Figure 7: Temperature ( $T$ unit: ${ }^{\circ} \mathrm{C}$ ), relative humidity $(\mathrm{RH}$, unit: $\%)$, and wind direction (unit: ${ }^{\circ}$ ) and wind speed (unit: $\mathrm{m} \cdot \mathrm{s}^{-1}$ ) profile of Xingtai Station when fog event occurred. (a) 2016123120 (BT). (b) 2017010108 (BT). (c) 2017010120 (BT). (d) 2017010208 (BT). (e) 2017010308 (BT). (f) 2017010320 (BT). (g) 2017010408 (BT). (h) 2017010420 (BT).

event develops upward, the inversion layer moves to the top of fog; that is to say, the fog top is in the inversion layer. Most of the fog tops are between $200 \mathrm{~m}$ and $300 \mathrm{~m}$. The thinner the fog is, the greater the intensity of the ground fog event is.

Low altitude warm and wet airflow often enhances the inversion intensity, which in turn enhances the intensity of ground fog event. There was weak cold air going south on the night of January 1, and the ground temperature obviously decreased. However, from the night of January 2, there was a strong warm and wet airflow above $200 \mathrm{~m}$, which increased the inversion intensity $\left(7.1^{\circ} \mathrm{C} / 100 \mathrm{~m}\right.$ at $08: 00$ on January 3$)$, and the fog event on the ground increased to EDF event. As mentioned earlier, there are two radiation fog areas in the study area on January 1; Xingtai Station, Leting Station, and Beijing Station are in the fog area of Hebei and Tianjin as the main fog areas. The fog top heights of the three stations are $338 \mathrm{~m}, 439 \mathrm{~m}$, and $369 \mathrm{~m}$, respectively, and the height of the inversion layer is $827 \mathrm{~m}, 860 \mathrm{~m}$, and $922 \mathrm{~m}$, respectively. Sheyang Sounding Station (SY in Figure 1) is located in the main fog area in the Jianghuai area of Jiangsu province, and the heights of fog top and inversion layer are $172 \mathrm{~m}$ and $554 \mathrm{~m}$, respectively. It can be observed that when the fog event is of the same type, the dissipation time of the fog event is related to the thickness of the fog. The height and inversion height of fog in Jiangsu area are lower than those in Hebei and Tianjin, which is one of the reasons why the SDF in Jiangsu area dissipates gradually at 12:00 after sunrise, while that in Hebei and Tianjin was still not dissipated; there are 53 SDF stations in this area at 12:00.

3.4. Generation and Dissipation of Fog Event. Figure 8 shows the time evolution of relative humidity, temperature, and wind direction and wind speed profile and visibility, temperature, humidity, and wind of the Tianjin Meteorological Tower from December 30, 2016, to January 5, 2017. The Tianjin Meteorological Tower is located in the red square in Figure 1. The length of time of the fog event of Tianjin Station is $76.3 \mathrm{~h}$, and strong dense fog event occurs for $24.3 \mathrm{~h}$; strong dense fog event occurred for a long 
TABLE 2: Inversion characteristics of the boundary layer in the fog event of Xingtai Sounding Station.

\begin{tabular}{|c|c|c|c|c|c|c|}
\hline Date & $\begin{array}{l}\text { Inversion bottom } \\
(\mathrm{m}) / T_{\mathrm{b}}\left({ }^{\circ} \mathrm{C}\right)\end{array}$ & $\begin{array}{l}\text { Inversion top } \\
(\mathrm{m}) / T_{\mathrm{t}}\left({ }^{\circ} \mathrm{C}\right)\end{array}$ & $\begin{array}{l}\text { Inversion thickness } \\
(\mathrm{m})\end{array}$ & $\begin{array}{l}\text { Inversion intensity } \\
\left({ }^{\circ} \mathrm{C} / 100 \mathrm{~m}\right)\end{array}$ & $\begin{array}{l}\text { Height of fog top } \\
(\mathrm{m})\end{array}$ & $\begin{array}{c}\text { Visibility } \\
(\mathrm{m})\end{array}$ \\
\hline $2016123108: 00$ & $0 /-3.8$ & $617 / 6.1$ & 617 & 1.6 & - & 1252 \\
\hline $2016123120: 00$ & $18 /-2.3$ & $349 / 8$ & 331 & 3.1 & 162 & 20 \\
\hline 20170101 08:00 & $208 /-4.7$ & $827 / 7.2$ & 619 & 1.9 & 338 & 61 \\
\hline $2017010120: 00$ & $187 /-3.0$ & $634 / 8.0$ & 447 & 2.5 & 282 & 119 \\
\hline 20170102 08:00 & $0 /-5.8$ & $399 / 6.8$ & 399 & 3.2 & 82 & 64 \\
\hline $2017010220: 00$ & $0 / 2.9$ & $953 / 7.1$ & 953 & 0.4 & - & 2053 \\
\hline 20170103 08:00 & $53 /-5.3$ & $291 / 11.7$ & 238 & 7.1 & 164 & 51 \\
\hline 20170103 20:00 & $40 /-2.2$ & $242 / 10.3$ & 202 & 6.2 & 97 & 34 \\
\hline 20170104 08:00 & $208 /-4.5$ & $574 / 6.8$ & 366 & 3.1 & 327 & 138 \\
\hline 20170104 20:00 & $221 /-2.6$ & $678 / 3.0$ & 457 & 1.2 & 297 & 412 \\
\hline
\end{tabular}
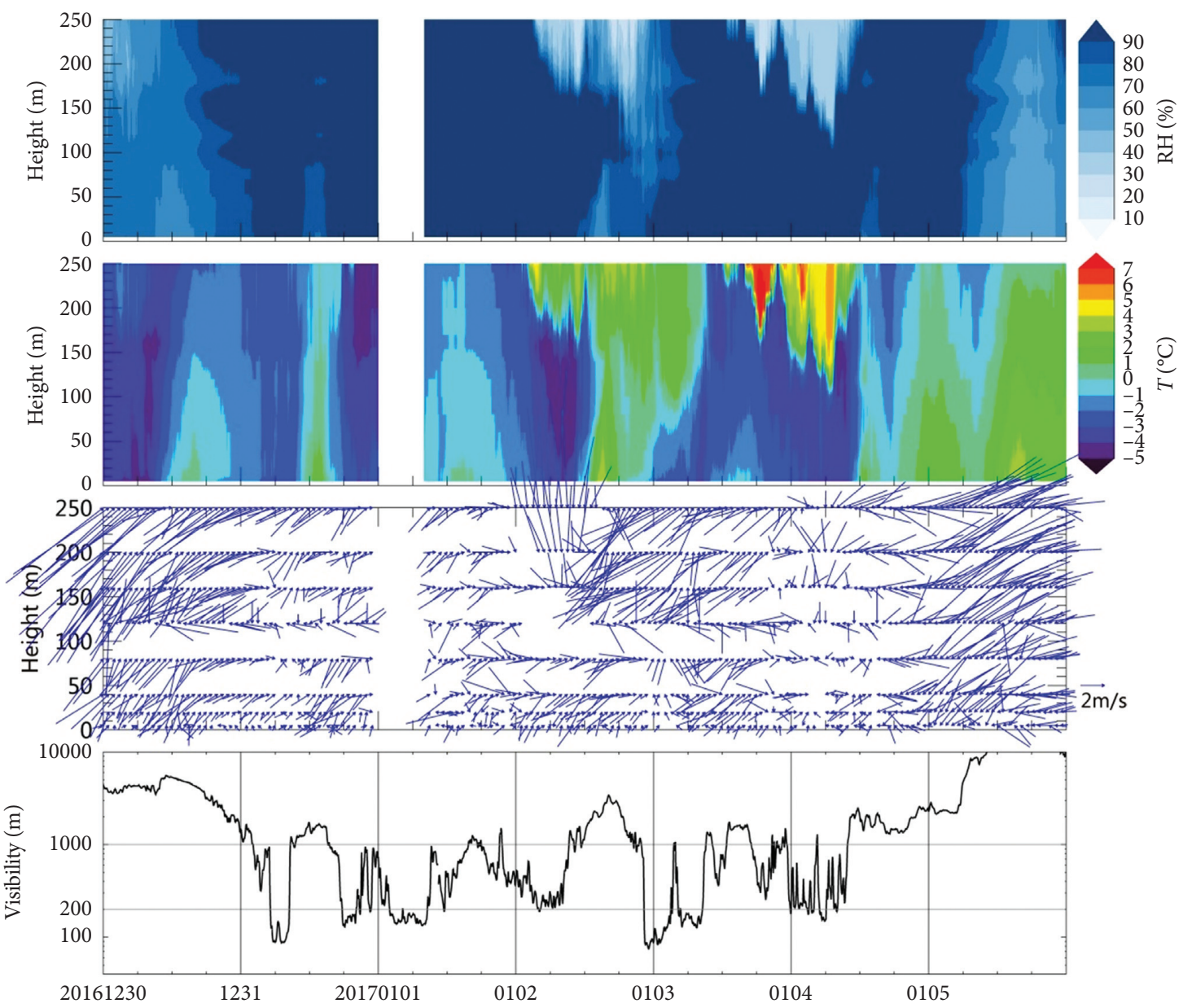

FIGURE 8: Evolution of relative humidity, temperature, and wind direction and wind speed profile and visibility of Tianjin Tower from December 30, 2016, to January 5, 2017.

time in the morning of December 31, from the night of December 31 to the morning of January 1, and from the night of January 2 to the morning of January 3. During the fog period, the surface wind speed was less than $2.0 \mathrm{~m} / \mathrm{s}$, the southward wind direction of weak cold air was north wind from January 1 to 2 , the wind direction at night of January 4 and January 5 was northward, and the wind direction was the southward wind at other times. From the time evolution diagram of relative humidity and temperature profile of Tianjin Tower, it can be observed that the evolution of humidity and temperature profile has a good consistency. When cooling, humidity increases, and visibility decreases; meanwhile humidity decreases, and visibility increases when the temperature increases. At 20:00 on December 30, the atmosphere above $100 \mathrm{~m}$ reached saturation, and at 02:00 on December 31, the ground reached saturation. The visibility of Tianjin Station decreased to less than $1000 \mathrm{~m}$ at 2:15 on 
December 31, and the relative humidity below $80 \mathrm{~m}$ was reduced to less than $90 \%$ due to the increase in ground temperature caused by solar radiation from 11:00 to 15: 00 on December 31. However, the atmosphere between $80 \mathrm{~m}$ and $250 \mathrm{~m}$ was still saturated, during which the visibility on the ground rose to about $1600 \mathrm{~m}$. After that, the whole atmosphere below $250 \mathrm{~m}$ reached saturation again and maintained the whole layer saturation for $36 \mathrm{~h}$ until 03:00 on January 2. The relative humidity at $250 \mathrm{~m}$ height firstly decreased to less than $90 \%$ and then expanded downward to the unsaturated layer; that is, the fog dissipated from the fog top and the fog top lowered down continuously. By 10:34, the relative humidity of the ground also began to be less than $90 \%$. At this time, the atmosphere above $180 \mathrm{~m}$ and ground were in a saturated condition, the middle layer was still saturated, and the visibility rose to more than $1000(1073 \mathrm{~m})$ at 10:30. After that, the surface unsaturated layer continued to rise, the upper unsaturated layer continued to decline, and the relative humidity of the whole layer decreased to less than $90 \%$ at $17: 56$. That is to say, due to the southward movement of the weak cold high pressure at 03:00 on January 2, the warm air in the upper layer sank and the temperature increased, and the temperature began to rise at the height of $250 \mathrm{~m}$, which caused the fog to dissipate from the height. As a result of solar radiation heating, the fog began to dissipate by 10:30, followed by a continuous decline in the upper layer and an increase in the surface layer; the fog dissipated by 17:56. By 22:41 on January 2, the ground reached saturation again, and the saturated layer was rising. By 7:26 on January 3, the whole layer reached saturation again; that is, fog event formed on the surface and continued to expand upward. By 17:30, the relative humidity of $250 \mathrm{~m}$ height dropped below $90 \%$ again, and the unsaturated layer continued to decline. By 6:40 on January 4, the unsaturated layer expanded to $120 \mathrm{~m}$, the saturated layer was still saturated, and then the saturated layer expanded upward. By 12:52, the whole layer was saturated again. The saturation state lasted until $5: 30$ on January 5 , and then the unsaturated layer began to appear on the ground and continued to expand upward, and the relative humidity of the whole layer decreased to less than $90 \%$ at 10:05. The wind speed at $200 \mathrm{~m}$ reached about $10.0 \mathrm{~m} / \mathrm{s}$ at 08:00 before the formation of fog event on December 30, and the wind direction was southwest and speed decreased gradually. When it was saturated at 20:00, the wind speed decreased to $4.0 \mathrm{~m} / \mathrm{s}$. Then, until the evening of January 1 , the wind speed was below $3.0 \mathrm{~m} / \mathrm{s}$, and the wind direction was southwest. From the early morning to noon on January 2, the weak cold air invaded, the wind direction turned to the north, the wind speed increased to about $5.0 \mathrm{~m} / \mathrm{s}$ and then turned to the southwest, and the wind speed gradually decreased. From the early morning of January 4 , affected by the cold air from the east, the wind direction changed to the northeast, and the wind speed increased to more than $3.0 \mathrm{~m} / \mathrm{s}$ and then gradually increased more. By 08:00 on January 5, the wind speed was above $8.0 \mathrm{~m} / \mathrm{s}$, and the visibility also improved to $8.6 \mathrm{~km}$.
From the above analysis, it can be observed that fog events can first occur in the upper layer and then expand to the ground, and they can also form on the ground and then expand to the high altitude. Fog dissipation can begin at the upper level, begin on the ground, or dissipate from the upper layer and the ground to the intermediate layer at the same time.

3.5. Serious Air Pollution. Another feature of this fog event is serious air pollution. Table 3 lists the daily mean concentration of $\mathrm{PM}_{2.5}$ in cities of Hebei province from December 30, 2016, to January 5, 2017. It can be seen that, except for Chengde city and Zhangjiakou city in northern Hebei (visibility of these two stations was above $3000 \mathrm{~m}$ during the study period, and no fog event occurred), the average $\mathrm{PM}_{2.5}$ concentration in other cities in Hebei province is severe $\left(>150 \mu \mathrm{g} / \mathrm{m}^{3}\right)$ or serious pollution $\left(>250 \mu \mathrm{g} / \mathrm{m}^{3}\right)$, among which the pollution was the most serious on December 31, 2016. The mass concentrations of $\mathrm{PM}_{2.5}$ in Shijiazhuang and Xingtai were above $400 \mu \mathrm{g} / \mathrm{m}^{3}$, and the concentrations of Baoding, Handan, Langfang, and Tangshan were above $300 \mu \mathrm{g} / \mathrm{m}^{3}$, while the minimum visibilities of Shijiazhuang, Xingtai, Baoding, Handan, Langfang, and Tangshan stations were $50 \mathrm{~m}, 19 \mathrm{~m}, 98 \mathrm{~m}, 53 \mathrm{~m}, 53 \mathrm{~m}$, and $91 \mathrm{~m}$, respectively. Thus, it can be observed that, for Hebei province, the spatial distribution of serious pollution and strong dense fog event was consistent. Figure 9 shows the time variation of visibility, $\mathrm{PM}_{2.5}$ concentration, and $\mathrm{RH}$ in Shijiazhuang Station in Hebei province and Yancheng Station in Jiangsu province from December 30, 2016, to January 5, 2017. The stronger the fog event intensity is, the higher the pollutant concentration is. The occurrence time of fog event in Shijiazhuang station was $131.3 \mathrm{~h}$, and the occurrence time of the strong dense fog event was $36.6 \mathrm{~h}$. the average daily concentrations of $\mathrm{PM}_{2.5}$ were $310.5 \mu \mathrm{g} / \mathrm{m}^{3}, \quad 498.8 \mu \mathrm{g} / \mathrm{m}^{3}, \quad 320.3 \mu \mathrm{g} / \mathrm{m}^{3}$, $289.8 \mu \mathrm{g} / \mathrm{m}^{3}, 267.9 \mu \mathrm{g} / \mathrm{m}^{3}, 305.5 \mu \mathrm{g} / \mathrm{m}^{3}$, and $289.4 \mu \mathrm{g} / \mathrm{m}^{3}$, respectively, which all belonged to serious pollution. The mass concentration of $\mathrm{PM}_{2.5}$ at 12:00 on December 31 was even $664 \mu \mathrm{g} / \mathrm{m}^{3}$. Besides, in the process of fog event, Beijing, Tianjin, Henan, Shandong, Jiangsu, and Anhui province were generally in severe and serious pollution; for example, the time of serious pollution orange alarm in Beijing lasted for more than $200 \mathrm{~h}$. Jinan city launched level-I red emergency warning on January 3, and temporary suspension measures were taken in primary and secondary schools and kindergartens.

Before this large-scale persistent SDF event, since the middle of December 2016, a widespread heavy aerosol pollution event gradually occurred in Henan, Shandong, Hebei, Tianjin, and Beijing. Fei et al. [37] revealed the temporal and spatial evolution of this haze event, indicating that the visibility data of meteorological stations have a great potential for real-time monitoring of large-scale aerosol pollution events. During this fog event ( $\mathrm{RH}>90 \%$, see Figure 9), the presence of aerosol pollution results in lower visibility. Elias et al. [7, 38] also revealed that the mean contribution to extinction in the fog was $20 \pm 15 \%$ from hydrated aerosols smaller than $2.5 \mu \mathrm{m}$ and $6 \pm 7 \%$ from larger aerosols. 
TABLe 3: Daily mean concentrations of $\mathrm{PM}_{2.5}$ in cities of Hebei province from December 30, 2016, to January 5, $2017\left(\mu \mathrm{g} / \mathrm{m}^{3}\right)$.

\begin{tabular}{|c|c|c|c|c|c|c|c|c|c|c|c|}
\hline Date & Shijiazhuang & Xingtai & Baoding & Handan & Hengshui & Cangzhou & Langfang & Tangshan & Qinghuangdao & Chengde & Zhangjiakou \\
\hline $2016-12-30$ & 310.5 & 248.2 & 228.9 & 206.2 & 192.1 & 159.7 & 199.5 & 166.7 & 170.1 & 61.3 & 47.9 \\
\hline $2016-12-31$ & 498.8 & 411.5 & 329.8 & 373.7 & 214.3 & 211 & 335.6 & 325.3 & 245.3 & 82.9 & 65.3 \\
\hline 2017-01-01 & 320.3 & 234.3 & 224.5 & 239.3 & 129.7 & 143.5 & 262.7 & 194.3 & 352.1 & 105.1 & 45.3 \\
\hline 2017-01-02 & 289.8 & 282.8 & 236.8 & 263.1 & 199.1 & 177.9 & 284.4 & 244.4 & 130.2 & 66.3 & 37.8 \\
\hline 2017-01-03 & 267.9 & 230.1 & 300.8 & 187 & 144.1 & 172.5 & 358.4 & 286.2 & 137.4 & 74.8 & 47.4 \\
\hline 2017-01-04 & 305.5 & 180.6 & 233.6 & 183.9 & 106.8 & 134.7 & 293.4 & 267.2 & 102 & 81.9 & 65.5 \\
\hline 2017-01-05 & 289.4 & 211.5 & 209.4 & 213.9 & 145.9 & 81.5 & 179.6 & 117 & 49.8 & 93.8 & 105.7 \\
\hline Average value & 326.0 & 257.0 & 252.0 & 238.2 & 161.7 & 154.4 & 273.4 & 228.7 & 169.6 & 80.9 & 59.3 \\
\hline
\end{tabular}

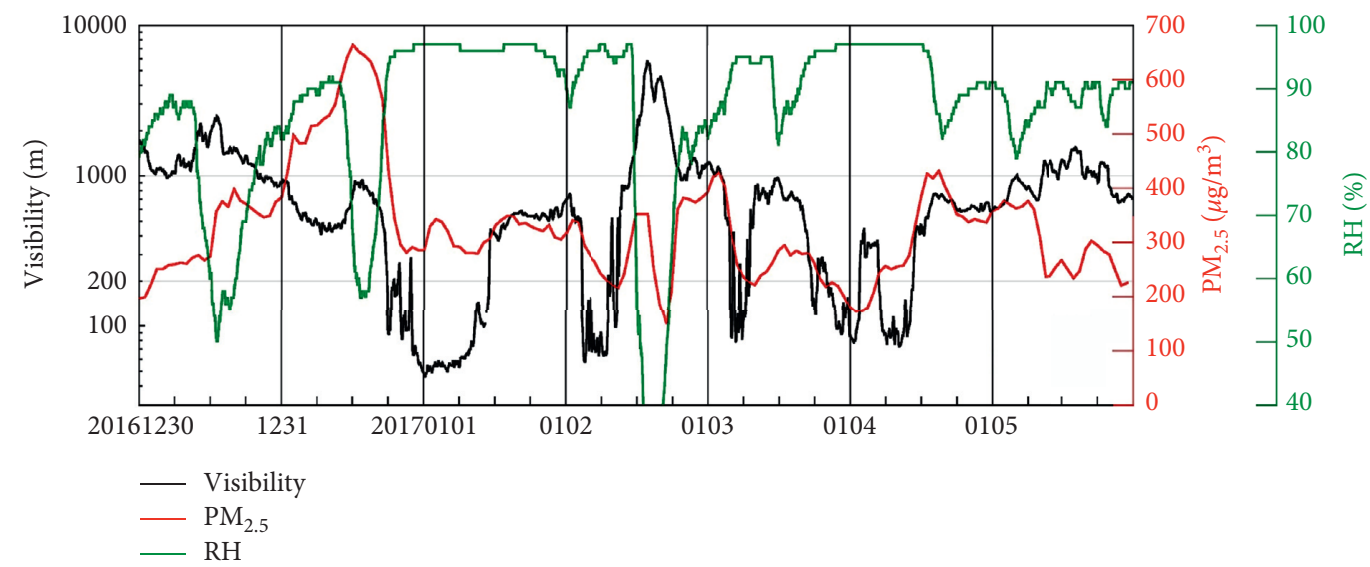

(a)

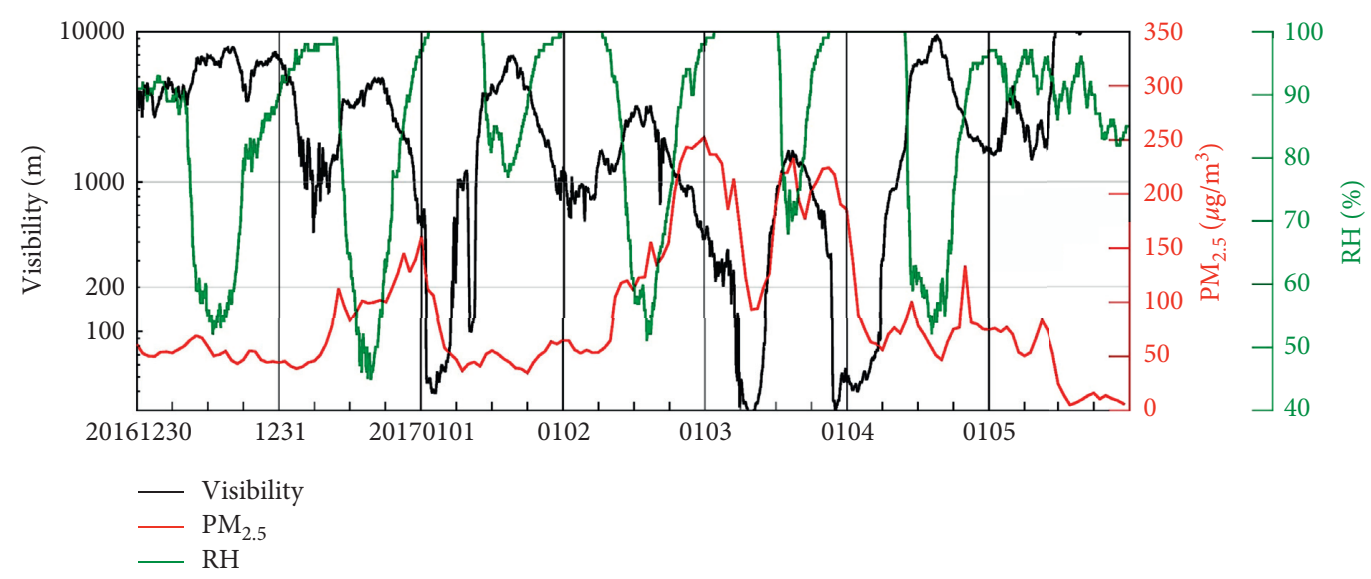

(b)

FIgURE 9: The variation of visibility (unit: $\mathrm{m}$ ), $\mathrm{PM}_{2.5}$ concentration (unit: $\mu \mathrm{g} / \mathrm{m}^{3}$ ), and $\mathrm{RH}$ (unit: \%) in Shijiazhuang, Hebei (a), and Yancheng, Jiangsu (b), from December 30, 2016, to January 5, 2017.

\section{Conclusions}

Based on the analysis of the characteristics of persistent strong dense fog event in central and eastern China from December 30, 2016, to January 5, 2017, the following can be concluded:

(1) Strong fog event has the characteristics of a wide range, high intensity, long duration, high-speed expansion, and serious air pollution. There are 531 stations with strong dense fog events, covering an area of over $360,000 \mathrm{~km}^{2}$ and lasting (Shenzhou Station in Hebei province) for $81.6 \mathrm{~h}$, with the characteristics of strong dense fog nondissipation during the day.

(2) Radiation fog and advection radiation fog alternately appeared in the process of strong fog event, and the first stage (20:00 on December 30 to 14:00 on January 1) was radiation fog event. The second stage (from 20:00 on January 1 to $08: 00$ on January 2) was affected by weak cold air intrusion, which was an 
advection radiation fog event. The third stage (from the night of January 2 to the day of January 3) was converted to a radiation fog event again. The fourth stage (from the night of January 3 to January 5) was affected by the cold air from the east, and it was radiative advection fog event again. After that, the cold air increased and the weak precipitation appeared, and the visibility became better.

(3) The synoptic system of fog event occurrence is that the central and eastern parts of China are in a wide range of pressure field. The fog in each place has an inversion layer that is stuck to the ground when the fog event occurs. After the fog event is formed, and with the upward development of the fog event, the inversion layer moves to the top of the fog, and the temperature in the fog has wet and heat-isolated distribution, and the fog top is in the inversion layer. In general, the stronger the inversion, the greater the intensity of the fog event on the ground. When warm and wet airflow blows above the fog top, the inversion intensity will increase, and the ground fog will be stronger. The top of the SDF is between 80 and 400 meters.

(4) Fog event can first occur in the upper layer and then expand to the ground, and it can also form on the ground and then expand to the high altitude. Fog dissipation can begin at the upper level, begin on the ground, or dissipate from the upper layer and the ground to the intermediate layer at the same time.

\section{Data Availability}

In this paper, the data of 915 stations in the study area of 2400 national meteorological stations in China $\left(110^{\circ}-123^{\circ} \mathrm{E}, 29^{\circ}-42^{\circ} \mathrm{N}\right)$ from December 30,2016 , to January 5,2017 , are used, including 5-minute resolution data of visibility, temperature, humidity, wind direction, and wind speed and 3 -hour resolution artificial observation data (including weather phenomena). The fine-resolution data of 16 radiosonde sounding stations (twice a day at 08 : 00 and 20:00 Beijing time) in the range of the study area are used. Also, the Tianjin Meteorological Tower Data are used. These data are available from the corresponding author upon request.

\section{Conflicts of Interest}

The authors declare that there are no conflicts of interest regarding the publication of this paper.

\section{Acknowledgments}

This work was jointly supported by the Natural Science Foundation of Jiangsu Province (Grant no. BK20161073), the 333 Project of Jiangsu Province (BRA2018420), the Basic Scientific Research Progress of the Chinese Academy of Meteorological Sciences (2019Z007), and the Key Projects of Jiangsu Meteorological Bureau (KZ201902 and KZ201907).

\section{References}

[1] R. Gautam and M. K. Singh, "Urban heat island over Delhi punches holes in widespread fog in the Indo-Gangetic plains," Geophysical Research Letters, vol. 45, no. 2, pp. 1114-1121, 2018.

[2] H. Kim, S. Collier, X. Ge et al., "Chemical processing of watersoluble species and formation of secondary organic aerosol in fogs," Atmospheric Environment, vol. 200, pp. 158-166, 2019.

[3] D. Y. Liu, W. L. Yan, J. Yang, M. J. Pu, S. J. Niu, and Z. H. Li, "A study of the physical processes of an advection fog boundary layer," Boundary-Layer Meteorology, vol. 158, no. 1, pp. 125-138, 2016.

[4] R. G. Eldridge, "A few fog drop-size distributions," Journal of Meteorology, vol. 18, no. 5, pp. 671-676, 1961.

[5] W. T. Roach, R. Brown, and S. J. Caughey, "On some quasiperiodic oscillations observed during a field investigation of radiation fog," Quarterly Journal of the Royal Meteorological Society, vol. 102, no. 432, pp. 355-359, 1976.

[6] J. G. Hudson, "Relationship between fog condensation nuclei and fog microstructure," Journal of the Atmospheric Sciences, vol. 37, no. 8, pp. 1854-1867, 1980.

[7] T. Elias, M. Haeffelin, P. Drobinski et al., "Particulate contribution to extinction of visible radiation: pollution, haze, and fog," Atmospheric Research, vol. 92, no. 4, pp. 443-454, 2009.

[8] M. Mohan and S. Payra, "Influence of aerosol spectrum and air pollutants on fog formation in urban environment of megacity Delhi, India," Environmental Monitoring and Assessment, vol. 151, no. 1-4, pp. 265-277, 2009.

[9] S. Stolaki, M. Haeffelin, C. Lac, J.-C. Dupont, T. Elias, and V. Masson, "Influence of aerosols on the life cycle of a radiation fog event. A numerical and observational study," Atmospheric Research, vol. 151, pp. 146-161, 2015.

[10] H.-B. Wang, Z.-W. Zhang, L. Zhang, H. Wu, L.-Y. Zhou, and F. $\mathrm{Zu}$, "Identify the size of aerosol particles and analyze its characteristics at three AERONET sites in China," China Environmental Science, vol. 35, no. 4, pp. 995-1003, 2015, in Chinese.

[11] Y. Y. Zhu, C. Y. Zhu, F. Zu et al., "A persistent fog event involving heavy pollutants in Yancheng area of Jiangsu province," Advances in Meteorology, vol. 2018, Article ID 2512138, 14 pages, 2018.

[12] J. Chen, C. S. Zhao, N. Ma et al., "A parameterization of low visibilities for hazy days in the north China plain," Atmospheric Chemistry and Physics, vol. 12, no. 11, pp. 4935-4950, 2012.

[13] X. Y. Gao, S. H. Gao, and Y. Yang, "A comparison between 3DVAR and EnKF for data assimilation effects on the Yellow Sea fog forecast," Atmosphere, vol. 9, no. 9, p. 346, 2018.

[14] Z. H. Li, "Studies of fog in China over the past 40 years," Acta Meteorologica Sinica, vol. 59, no. 5, pp. 616-624, 2001, in Chinese.

[15] Z. H. Li, D. Y. Liu, and J. Yang, "The microphysical processes and macroscopic conditions of the radiation fog droplet spectrum broadening," Chinese Journal of Atmospheric Sciences, vol. 35, no. 1, pp. 41-54, 2011, in Chinese.

[16] D. Y. Liu, M. J. Pu, and J. Yang, "Microphysical structure and evolution of a four-day persistent fog event in Nanjing in December 2006," Journal of Meteorological Research, vol. 24, no. 1, pp. 104-115, 2010, in Chinese.

[17] D. Y. Liu, J. Yang, S. J. Niu, and Z. Li, "On the evolution and structure of a radiation fog event in Nanjing," Advances in Atmospheric Sciences, vol. 28, no. 1, pp. 223-237, 2011. 
[18] D. Y. Liu, S. J. Niu, J. Yang, L. J. Zhao, J. J. Lu, and C. S. Lu, "Summary of a 4-year fog field study in northern Nanjing, Part 1: fog boundary layer," Pure and Applied Geophysics, vol. 169, no. 5-6, pp. 809-819, 2012.

[19] B. Thierry and L. Renaud, "On the predictability of radiation fog formation in a mesoscale model: a case study in heterogeneous terrain," Atmosphere, vol. 10, no. 4, p. 165, 2019.

[20] Z. H. Li and J. Wu, "Winter fog droplet spectrum features in urban area of Chongqing," Journal of Nanjing Institute of Meteorology, vol. 18, no. 1, pp. 46-51, 1995, in Chinese.

[21] Z. H. Li, J. P. Huang, and Y. Q. Zhou, "Physical structures of the five-day sustained fog around Nanjing in 1996," Acta Meteorologica Sinica, vol. 57, no. 5, pp. 622-631, 1999, in Chinese.

[22] J. Yang, Z. Q. Niu, and C. E. Shi, "Microphysics of atmospheric aerosols during winter haze/fog events in Nanjing," Environmental Science, vol. 31, no. 7, pp. 1425-1431, 2010, in Chinese.

[23] R. G. Eldridge, "The relationship between visibility and liquid water content in fog," Journal of the Atmospheric Sciences, vol. 28, no. 7, pp. 1183-1186, 1971.

[24] H. Gerber, "Supersaturation and droplet spectral evolution in fog," Journal of the Atmospheric Sciences, vol. 48, no. 24, pp. 2569-2588, 1991.

[25] K. E. Pickering and J. E. Jiusto, "Observations of the relationship between dew and radiation fog," Journal of Geophysical Research: Oceans, vol. 83, no. C5, pp. 2430-2436, 1978.

[26] S. Egli, F. Maier, J. Bendix, and B. Thies, "Vertical distribution of microphysical properties in radiation fogs-a case study," Atmospheric Research, vol. 151, pp. 130-145, 2015.

[27] X. Ye, B. Wu, and H. Zhang, "The turbulent structure and transport in fog layers observed over the Tianjin area," Atmospheric Research, vol. 153, pp. 217-234, 2015.

[28] Z. H. Li, D. Y. Liu, W. L. Yan et al., "Dense fog burst reinforcement over Eastern China: a review," Atmospheric Research, vol. 230, Article ID 104639, 2019.

[29] D. Wu, X. J. Wu, and F. Li, "Temporal and spatial variation of haze during 1951-2005 in Chinese mainland," Acta Meteorologica Sinica, vol. 68, no. 5, pp. 680-688, 2010, in Chinese.

[30] D. $\mathrm{Wu}, \mathrm{X}$. J. Wu, and F. Li, "Long-term variation of fog and mist in 1951-2005 in mainland China," Journal of Tropical Meteorology, vol. 27, no. 2, pp. 145-151, 2011.

[31] Y. H. Ding and Y. J. Liu, "Analysis of long-term variations of fog and haze in China in recent 50 years and their relations with atmospheric humidity," Science China Earth Sciences, vol. 57, no. 1, pp. 36-46, 2014, in Chinese.

[32] S. M. Jiao, C. Y. Zhu, Y. Y. Zhu, C. S. Yuan, and F. Zu, “A discussion on the reason for a rare persistent heavy fog event in Jiangsu Province," Acta Meteorologica Sinica, vol. 74, no. 2, pp. 200-212, 2016, in Chinese.

[33] R. H. Zhang, Q. Li, and R. N. Zhang, "Meteorological conditions for the persistent severe fog and haze event over eastern China in January 2013," Science China Earth Sciences, vol. 57, no. 1, pp. 26-35, 2014, in Chinese.

[34] M. Liu, W. L. Yan, and B. Zhang, "Analysis on persistence and intensification mechanism of fog and haze in Jiangsu in January 2013," Meteorological Monthly, vol. 40, no. 7, pp. 835-843, 2014.

[35] C. P. Ma, B. G. Wu, and Y. C. Li, "Mechanisms of formation and maintenance of 12-day long-drawn fog in central and southern Hebei Province," Plateau Meteorology, vol. 31, no. 6, pp. 1663-1674, 2012, in Chinese.
[36] B. G. Wu, H. S. Zhang, and J. Wang, "Characteristics of the inversion and the water vapor transport during a duration fog event," Plateau Meteorology, vol. 28, no. 2, pp. 258-267, 2009, in Chinese.

[37] Y. Fei, D. Fu, Z. Song, S. Han, X. Han, and X. Xia, "Spatiotemporal variability of surface extinction coefficient based on two-year hourly visibility data in mainland China," Atmospheric Pollution Research, vol. 10, no. 6, pp. 1944-1952, 2019.

[38] T. Elias, J.-C. Dupont, E. Hammer et al., "Enhanced extinction of visible radiation due to hydrated aerosols in mist and fog," Atmospheric Chemistry and Physics, vol. 15, no. 12, pp. 6605-6623, 2015. 